ISSN: 1679-3013

D.O.I.: 10.5914/1679-3013.2012.0070

\title{
ESTUDO DO FLUXO LARVAL DE BRAQUIÚROS NO CANAL DE ACESSO AO ESTUÁRIO DA LAGOA DOS PATOS, RIO GRANDE, RIO GRANDE DO SUL, BRASIL.
}

\author{
Pedro Henrique Viana de ARAÚjO1,2 \\ José Henrique MUELBERT ${ }^{1,2}$ \\ Danilo Koetz de CALAZANS ${ }^{1,3}$
}

Recebido em: 04/03/2012

Aceito em: 10/09/2012

\section{RESUMO}

Dentre os grupos faunísticos de ambientes estuarinos destacam-se os braquiúros que apresentam duas fases larvais planctônicas. No estuário da Lagoa dos Patos são reportadas 23 espécies de larvas que estão sujeitas aos processos físicos de circulação das correntes. Foram coletadas amostras físicas e biológicas durante 24 horas a cada três horas com o objetivo de estudar o fluxo larval no Canal de Acesso ao estuário. 0 Canal se encontrava em sistema de vazão, ventos de nordeste e nível acima de zero durante o estudo. Foram identificadas larvas de dez espécies de braquiúros que estavam continuamente sendo exportadas para o oceano adjacente preferencialmente pela região do Molhe Oeste na camada da superfície. O fluxo total de larvas foi 623.630 ind.100 $\mathrm{m}^{-2} \mathrm{~s}^{-1}$ e as espécies mais abundantes foram Armases rubripes e Neohelice granulata. Foi observada a retenção larval de Rhithropanopeus harrisii e o primeiro registro de zoé 1 de Stenorhynchus seticornis no interior da lagoa.

Palavras chave: Lagoa dos Patos, Braquiúros, Larvas, Fluxo, Exportação.

\section{ABSTRACT}

Brachyura is among the relevant fauna of estuarine environments, with two planktonic larval stages. At the Lagoa dos Patos estuary 23 brachyuran larval species are reported, and their transport is subject to physical processes and circulation. Physical and biological samples were collected at every three hours during 24 hours, with the objective to study larval flux in the access channel to the estuary. Channel condition during the study were of water runoff, winds from the Northeast and water level above zero. Brachyuran larvae of ten species were identified, which were continuously exported to the adjacent Ocean, preferably through the surface layer in the western region of the channel. The total larval flux was $623.629,77$ ind.100 $\mathrm{m}^{-2} \mathrm{~s}^{-1}$ and the most abundant species were Armases rubripes and Neohelice granulata. Larval retention of Rhithropanopeus harrisii was observed and the first record of zoe1 of Stenorhynchus seticornis within the lagoon is reported.

Palavras chave: Lagoa dos Patos, Brachyuran, Larval, Flux, Exported.

\section{INTRODUÇÃO}

Dentre os grupos faunísticos que habitam ambientes estuarinos destacam-se os crustáceos braquiúros por sua contribuição fundamental para a complexidade e funcionamento dos ecossistemas tropicais (Hendrickx, 1995). Esta contribuição é devida a sua participação na ciclagem de nutrientes e de matéria orgânica, como também serem utilizados como alimentos por humanos e peixes de importância econômica (Caddy, 1989). As espécies da Infraordem Brachyura (Latreille, 1803), pertencente à Classe Crustacea, possui ampla distribuição geográfica e ocorre em todos os continentes com 6.793 espécies ( $\mathrm{Ng}$ et al., 2008). No estudo de Vieira (2006) sobre a ecologia das fases

1- Instituto de Oceanografia - Universidade Federal do Rio Grande - FURG. Av. Itália Km 8, Caixa Postal 474, Rio Grande - RS - Brasil. 2 - Laboratório de Ecologia do Ictioplânton. 3 - Laboratório de Crustáceos Decápodos. 
ARAÚjO, P. H. V. de; MUELBERT, J. H.; CALAZANS, D. K. de. Estudo do fluxo larval de braquiúros no canal de acesso ao estuário da Lagoa dos Patos, Rio Grande, Rio Grande do Sul, Brasil..

de braquiúros no estuário da Lagoa dos Patos e região costeira, o autor contabilizou larvas meroplanctônicas de 23 espécies de braquiúros pertencentes a 10 famílias. As mais abundantes foram as zoés e megalopas de Hexapanopeus cribaeus (Panopeidae) e Neohelice granulata (Varunidae) e as zoés do gênero Pinnixa (Pinnotheridea).

Os braquiúros em geral apresentam ritmos de emissão larval, que promovem um sincronismo na liberação das larvas no ambiente pelágico de acordo com fenômenos ambientais periódicos, como os ciclos diários, lunares, de marés e os de amplitude de maré (Paula, 1989; Forward et al., 1982; Saigusa et al., 2003). Estas larvas são transportadas através de mecanismos físicos como marés, tempestades, correntes dirigidas pelo vento, circulação de Langmuir, ondas internas, redemoinho e descarga de água continental (Rougharden et al., 1988). Segundo López \& Coutinho (2008) o suprimento de larvas numa determinada região é definido por diversos meios de transporte larval: "offshore", "onshore" e retenção, associadas ao poder de natação das larvas e das condições oceanográficas da região. Estes transportes geram um fluxo, que é estimado através de medições repetitivas da abundância larval e da velocidade das correntes numa área conhecida (Rowe \& Epifanio, 1994).

Papadopoulos et al. (2002) destacou a importância dos processos de transporte na comunicação entre estuário e oceano no recrutamento e na manutenção destes organismos no ambiente. Um bom exemplo disso é quando as zoés de Callinectes sapidus que eclodem no interior do estuário são transportadas para a região costeira adjacente por correntes de superfície na Lagoa dos Patos (Viera, 2006), como também ocorre na baia Cheasapeake (Roman \& Boicourt, 1999). O contrário acontece quando as zoés desta mesma espécie que ocorrem na região costeira adjacente são transportadas para dentro do estuário na fase de megalopa na Lagoa dos Patos (Vieira, 2006), ou podem ser exportadas para a região costeira como zoés e futuramente reinvadir o estuário como acontece na Baia de Delaware (Epifanio et al. 1984).

Nos últimos vinte anos os estudos sobre os mecanismos de transporte larval de crustáceos foram intensificados, com o intuito de compreender a dinâmica populacional dos adultos para fins ecológicos e econômicos (Levin, 2006). Desta forma alguns trabalhos têm sido feitos para estudar o fluxo larval de decápodos nas áreas costeiras ao redor do mundo (Christy \& Stancyk, 1982; Dittel et al., 1991; Negreiros-Fransozo et al., 2002; Paula et al., 2004). Os estudos sobre fluxo larval em estuários do Brasil iniciou-se com Freire em 1998, com a espécie Ucides cordatus em manguezais da Baía de Paranaguá. Schwamborn et al. (2008) estudou pela primeira vez a modelagem e a quantificação do transporte decápodes associado aos dados de um Perfilador de Correntes Acústico pelo efeito Doppler (ADCP) na Barra de Catuama. De acordo com este autor, a associação entre dados biológicos e físicos oriundos de ADCP pode ser um meio eficaz de investigar a dinâmica e os padrões de transporte de decápodos em áreas estuarinas.

Até hoje é inédita a relação entre perfis de velocidades de correntes gerados por um ADCP com o fluxo larval de braquiúros nos diversos estágios de desenvolvimento. Por outro lado, a importância dos processos de transporte no ciclo de vida de braquiúros, torna necessário compreender o fluxo dessas espécies no cenário de circulação de correntes em canais estuarinos. Desta forma, este trabalho tem objetivo de estudar o fluxo larval no Canal de Acesso à Lagoa dos Patos reforçando os estudos de ecologia larval e iniciando esse tipo de investigação para a região sul do Brasil.

\section{ÁREA DE ESTUDO}

A Lagoa dos Patos, situada no Estado do Rio Grande do Sul (Figuras 1A e 1B), é a maior laguna costeira do Brasil e está conectada ao oceano adjacente através de um canal com $22 \mathrm{~km}$ de extensão, sendo considerada do tipo estrangulada (Kjervfe, 1986). A área estuarina possui cerca de $10 \%$ do corpo lagunar (Closs, 1966) com profundidade média de 1,74 m (Bonilha, 1996) (Figura 1C).

Esta região é caracterizada por um estoque pesqueiro demersal (Haimovici, 1998) e pelágico (Castello, 1990) de importância significativa na costa brasileira, a qual 
ARAúJO, P. H. V. de; MUELBERT, J. H.; CALAZANS, D. K. de. Estudo do fluxo larval de braquiúros no canal de acesso ao estuário da Lagoa dos Patos, Rio Grande, Rio Grande do Sul, Brasil.

desempenha um importante papel nos primeiros estágios do ciclo de vida de muitas espécies de peixe. Desta forma, acredita-se que esta é uma região de grande importância para o crescimento de diversas espécies de peixes e crustáceos (Castello \& Möller, 1978; Calazans, 1984; Muelbert \& Weiss, 1991; Vieira \& Castello, 1996) notadamente por abrigar as larvas destes que ali se desenvolvem e se alimentam.

A dinâmica da lagoa depende essencialmente do vento e da descarga fluvial, não sendo a maré, de caráter micromareal, uma componente importante na circulação estuarina local (Kjerfve, 1986; Möller et al., 1991; Möller et al., 1996; Zavialov et al., 2002). Os ventos de nordeste são predominantes na região ao longo de todo o ano (Tomazelli, 1993), no entanto há uma alta variabilidade sazonal e interanual (Braga \& Krusche, 2000; Piola et al., 2005) que influenciam na entrada e saída de água no interior do estuário (Motta, 1969; Möller et al., 2008). Os rios afluentes da Lagoa dos Patos drenam uma área de mais de $200.000 \mathrm{~km}^{2}$ (Vieira \& Rangel, 1988) com aporte máximo no inverno e primavera com valores a cima de $3.000 \mathrm{~m}^{3} \mathrm{~s}^{-1}$ e mínimo no verão e outono com vazão de $1.000 \mathrm{~m}^{3} \mathrm{~s}^{-1}$ (Herz, 1977; Marques, 2005; Vaz et al., 2006). A salinidade média do estuário é de 13, com valores variando de 0 a 34 (Castello, 1985) e a temperatura varia sazonalmente com valores em torno de $25,5^{\circ} \mathrm{C}$ no verão e cerca de $10^{\circ} \mathrm{C}$ no inverno (Möller \& Castaing, 1999).

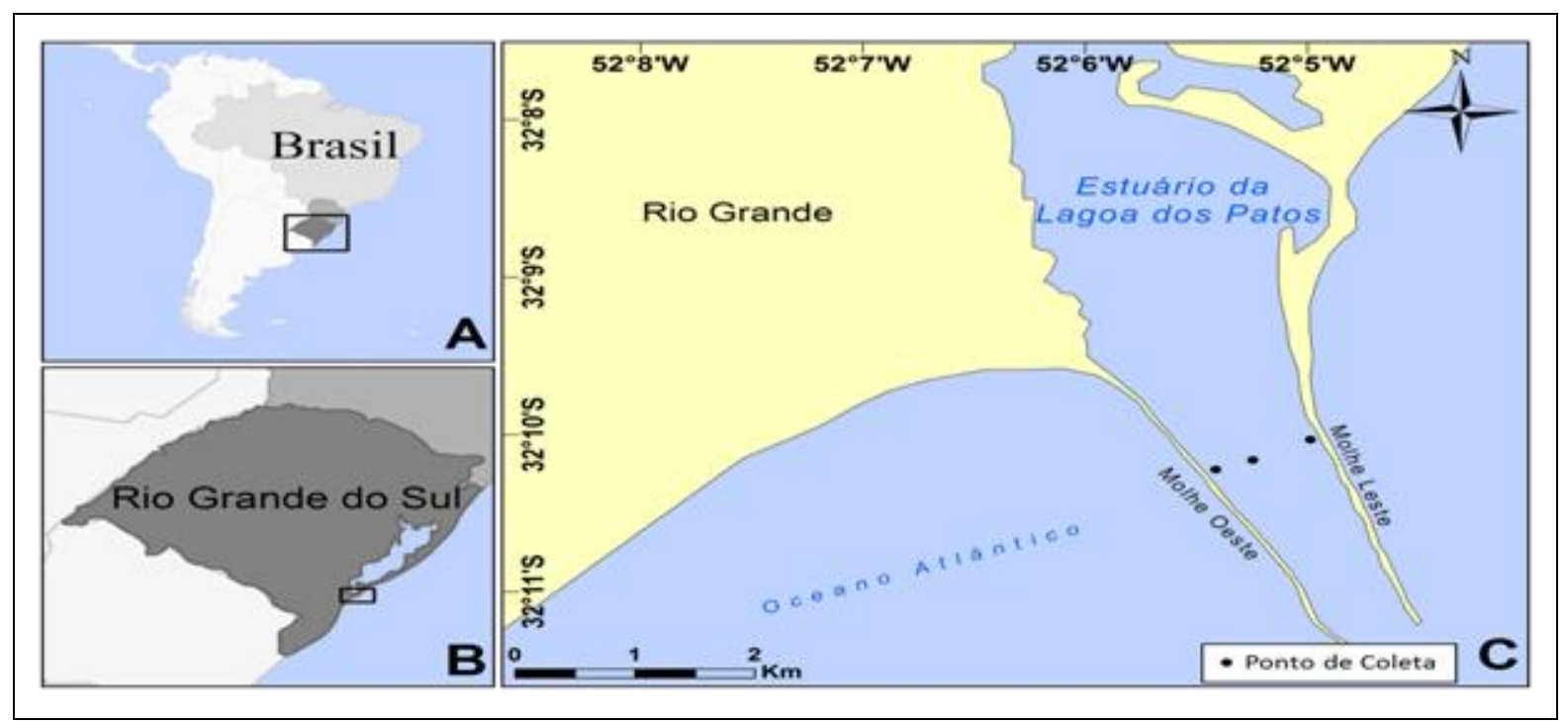

Figura 1 - Localização da Área de Estudo. A) O estado do Rio Grande do Sul inserido no mapa do Brasil; B) Mapa do Rio Grande do Sul destacando o Canal de Acesso à Lagos dos Patos e; C) Canal de Acesso à Lagoa dos Patos evidenciando os três pontos de coleta: L, Molhe Leste; C, Centro do Canal e; O, Molhe Oeste.

\section{MATERIAL E MÉTODOS}

As coletas foram realizadas entre às $14 \mathrm{~h} 30 \mathrm{~min}$ do dia 04/03/2010 até às $11 \mathrm{~h} 30 \mathrm{~min}$ do dia 05/03/2010 em três estações dispostas numa linha transversal $(700 \mathrm{~m})$ ao Canal de Acesso e dispostos três pontos de coleta (Figura 1C). O primeiro ponto foi localizado nas proximidades do Molhe Oeste; o segundo situado no centro do Canal de Acesso e; o terceiro nas proximidades do Molhe Leste, os quais foram visitados com a Lancha Oceanográfica "Larus". Este procedimento foi repetido a cada três horas, onde foram realizados arrastos de material zooplanctônico e coletados dados de temperatura, salinidade e velocidade de corrente. Totalizando 48 amostras biológicas e 8 perfis de velocidade.

\section{Dados Físicos}

Dados de salinidade e temperatura da água foram obtidos com a partir de um termosalinometro (YSI 30) com erro de 0,01. Os perfis de correntes e vazão foram obtidos a partir de um Perfilador Acústico por Efeito Doppler (ADCP) modelo SonTek/YSI 
ARAÚjO, P. H. V. de; MUELBERT, J. H.; CALAZANS, D. K. de. Estudo do fluxo larval de braquiúros no canal de acesso ao estuário da Lagoa dos Patos, Rio Grande, Rio Grande do Sul, Brasil..

de $1500 \mathrm{KHz}$ com Garmin GPSMap 276C rebocado na superfície ao longo da transversal ao canal de acesso. $O$ aparelho foi configurado para 30 células de $0,6 \mathrm{~m}$ de altura.

Os dados perfis de correntes foram extraídos através do programa SonTek ViewADP Standard versão 4.03 , onde foram previamente tratados para remoção de picos espúrios e suavizados através do filtro Gaussian a $25 \%$. A extração dos dados teve como referência a velocidade registrada pelo GPS (Andrade, 2010; Schmitt, 2010). Os dados tratados foram processados no programa MATLAB versão R2001a, resultando os gráficos de perfil de velocidade. Devido às dificuldades de se locomover sempre na mesma transversal e a movimentação do fundo lodoso da lagoa, os perfis de velocidade possuem escalas geográficas e configurações variáveis.

As séries de dados de velocidade do vento e nível da coluna de água foram cedidas pela Estação de Práticos da Barra do Rio Grande através de um convênio de cooperação com o Núcleo de Oceanografia Física da FURG. Os dados foram processados através de rotinas no programa MATLAB versão R2001a, onde foram gerados os gráficos.

\section{Dados Biológicos}

Em cada ponto foram realizados arrastos horizontais de superfície e de fundo com uma rede cilindrocônica de $60 \mathrm{~cm}$ de diâmetro e malha de $300 \mu \mathrm{m}$, dotado de um fluxômetro e mecanismo de fechamento. A duração dos arrastos variou de 2 a 3 minutos de acordo com a concentração de material em suspensão para evitar colmatação da rede. $\mathrm{O}$ arrasto horizontal de superfície ocorreu logo no primeiro metro de profundidade, enquanto que para os arrastos de fundo foi primeiramente detectado o fundo através de uma ecossonda instalada na lancha e após foi estimada a profundidade do arrasto de fundo através do produto do cabo da rede pelo do ângulo que o mesmo formava com a lancha.

As amostras foram triadas, na sua totalidade, através de um microscópio estereoscópico com auxílio de uma placa do tipo "Bogorov". A identificação das larvas e a determinação das fases e estágios foram realizadas através de chaves sistemáticas dicotômicas elaboradas por Vieira (2006), Vieira \& Calazans (2010) e Koettker et al. (2012) com auxílio de um microscópio biológico OLYMPUS BX50 equipado com filtro Nomarsky. Os dados biológicos foram inicialmente expressos na forma de abundância padronizada (ind.100 $\mathrm{m}^{-3}$ ) e posteriormente transformados em fluxo (ind.100 $\mathrm{m}^{-2} \mathrm{~s}^{-1}$ ) através do produto entre a abundância e a velocidade da corrente $\left(\mathrm{ms}^{-1}\right)$ para cada amostra. A frequência de ocorrência foi calculada pela divisão entre $N^{\circ}$ de amostras contendo larvas sobre o total de amostras triadas.

A diversidade de Shannon $\left(\mathrm{H}^{\prime}\right)$ para cada transversal e ponto amostrado foi obtida utilizando as abundâncias padronizadas das amostras, sendo calculado com a base de logaritmos naturais e expresso em nats.ind ${ }^{-1}$. A análise de agrupamento (CLUSTER) para as transversais e pontos amostrados foi realizada com base em uma matriz de similaridade calculada pela similaridade de Bray-Curtis. Ambas as análises foram feitas através do programa estatístico Primer ${ }^{\circledR}$ (Plymouth Routines in Multivariate Ecological Research), versão 6.1.6.

\section{Outras Análises}

A variação dos dados de temperatura, salinidade, vazão, abundância e fluxo larval, assim como a correlação de Pearson da Diversidade de Shannon entre a Vazão Líquida e - Fluxo Médio Larval foram calculados pelo programa STATISTICA versão 7.0. Os histogramas dos fluxos larvais foram confeccionados pelo programa Microsoft Excel 2010. A plotagem desses histogramas nos perfis de velocidades foi feita com auxílio do programa Microsoft PowerPoint 2010. 
ARAÚJO, P. H. V. de; MUELBERT, J. H.; CALAZANS, D. K. de. Estudo do fluxo larval de braquiúros no canal de acesso ao estuário da Lagoa dos Patos, Rio Grande, Rio Grande do Sul, Brasil.

Tabela 1 - Profundidade em metros dos arrastos horizontais de fundo. Ponto $L$, Molhe Leste; C, Centro do Canal e; O, Molhe Oeste.

\section{DATA TRANSVERSAL PONTO PROFUNDIDADE DE ARRASTO (m)}

\begin{tabular}{|c|c|c|c|}
\hline $04 / 03 / 2010$ & 1 & $\mathrm{~L}$ & 12,50 \\
\hline $04 / 03 / 2010$ & 1 & $\mathrm{C}$ & 12,73 \\
\hline 04/03/2010 & 1 & 0 & 5,00 \\
\hline $04 / 03 / 2010$ & 2 & $\mathrm{~L}$ & 8,49 \\
\hline $04 / 03 / 2010$ & 2 & $\mathrm{C}$ & 10,61 \\
\hline $04 / 03 / 2010$ & 2 & 0 & 5,00 \\
\hline 04/03/2010 & 3 & $\mathrm{~L}$ & 7,50 \\
\hline $04 / 03 / 2010$ & 3 & $\mathrm{C}$ & 12,86 \\
\hline 04/03/2010 & 3 & 0 & 7,50 \\
\hline 04/03/2010 & 4 & $\mathrm{~L}$ & 6,50 \\
\hline 04/03/2010 & 4 & $\mathrm{C}$ & 12,86 \\
\hline $04 / 03 / 2010$ & 4 & 0 & 7,71 \\
\hline $05 / 03 / 2010$ & 5 & $\mathrm{~L}$ & 8,49 \\
\hline $05 / 03 / 2010$ & 5 & $\mathrm{C}$ & 10,00 \\
\hline $05 / 03 / 2010$ & 5 & $\mathrm{O}$ & 6,00 \\
\hline $05 / 03 / 2010$ & 6 & $\mathrm{~L}$ & 6,00 \\
\hline $05 / 03 / 2010$ & 6 & C & 11,57 \\
\hline $05 / 03 / 2010$ & 6 & 0 & 5,00 \\
\hline $05 / 03 / 2010$ & 7 & $\mathrm{~L}$ & 7,50 \\
\hline $05 / 03 / 2010$ & 7 & C & 9,00 \\
\hline $05 / 03 / 2010$ & 7 & 0 & 6,43 \\
\hline $05 / 03 / 2010$ & 8 & $\mathrm{~L}$ & 7,50 \\
\hline $05 / 03 / 2010$ & 8 & $\mathrm{C}$ & 9,00 \\
\hline $05 / 03 / 2010$ & 8 & 0 & 7,07 \\
\hline
\end{tabular}

\section{RESULTADOS}

\section{Dados Físicos}

Antes do período de estudo o estuário da Lagoa dos Patos estava sob influência de ventos do quadrante norte e com nível da água acima de zero. Durante o estudo a velocidade média do vento foi de $8,4 \mathrm{~ms}^{-1}$ (desvio padrão 4,1 ) que foi diminuindo de intensidade, tendendo a mudar de sentido e direção no fim do estudo. O nível da água apresentou comportamento de maré diurno com valor médio de $0,32 \mathrm{~m}$ (desvio padrão 0,11 ), possuindo maiores valores no início do estudo e menores no fim (Figura 2). 
ARAúJO, P. H. V. de; MUELBERT, J. H.; CALAZANS, D. K. de. Estudo do fluxo larval de braquiúros no canal de acesso ao estuário da Lagoa dos Patos, Rio Grande, Rio Grande do Sul, Brasil..

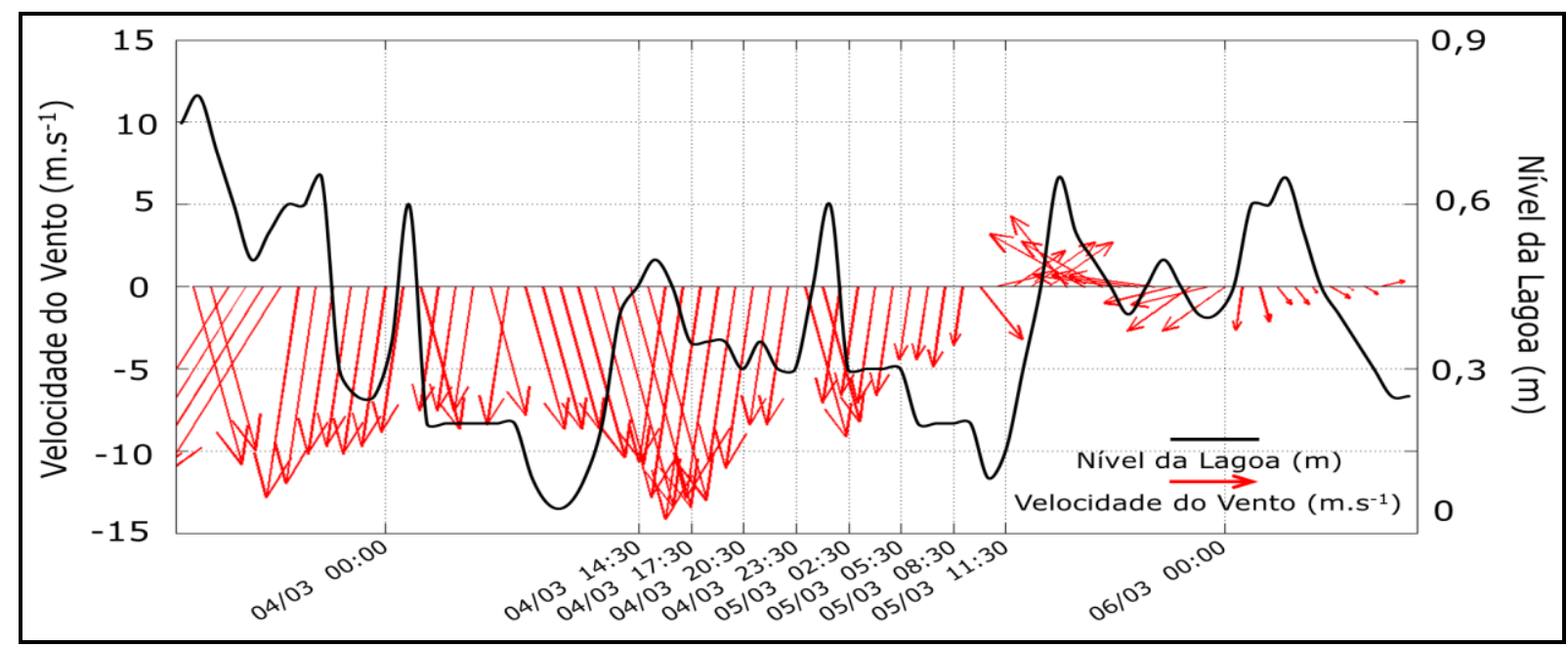

Figura 2: Gráfico da Variação da Velocidade do Vento $\left(\mathrm{ms}^{-1}\right)$ e da Variação do Nível da Lagoa dos Patos $(\mathrm{m})$ no período de 12:00 do dia 03/03/2010 às 12:00 de 06/03/2010.

A vazão líquida na transversal ao longo do Canal foi predominantemente de vazante com valor médio de $-135,5 \mathrm{~m}^{3} \mathrm{~s}^{-1}$ (desvio padrão 64,51 ), entretanto podem-se observar alguns momentos de estratificação vertical com a presença de cunha salina, que se encontrava em torno dos 15 metros de profundidade com espessura média de $2,33 \mathrm{~m}$ (desvio padrão 1,04) (Figura $3 \mathrm{~A}-3 \mathrm{H}$ ). As maiores velocidades de corrente foram registradas próximas à superfície do Molhe Oeste e do Centro do Canal com valor médio de $0,114 \mathrm{~ms}^{-1}$ (desvio padrão 20,89). Na região do Molhe Leste assim como nas regiões próximas ao fundo do canal foram observadas as menores velocidades com valor médio de $0,012 \mathrm{~ms}^{-1}$ (desvio padrão11,36). (Figuras $3 \mathrm{~A}-3 \mathrm{H}$ ).

A água do Canal de Acesso foi caracterizada como oligohalina (Esteves 1998) devido aos baixos valores de salinidade, com média de 0,7 (desvio padrão 0,3 ). A temperatura média registrada foi de $25^{\circ} \mathrm{C}$ (desvio padrão 0,2 ) (Tabela 1 ).

Tabela 2 - Valores de Temperatura $\left({ }^{\circ} \mathrm{C}\right)$ e Salinidade para o período de estudo nos pontos e estratos amostrados

\begin{tabular}{c|cccccc|cccccc|cccccc}
\hline & \multicolumn{6}{|c|}{ Molhe Leste } & \multicolumn{5}{c|}{ Centro do Canal } & \multicolumn{5}{|c}{ Molhe Leste } \\
\hline & S & M & F & S & M & F & S & M & F & S & M & F & S & M & F & S & M & F \\
\hline & Sal & T & Sal & T & Sal & T & Sal & T & Sal & T & Sal & T & Sal & T & Sal & T & Sal & T \\
1 & 1,1 & 25,1 & 1,2 & 25,0 & 1,2 & 25,0 & 0,8 & 25,0 & 0,8 & 25,0 & 0,9 & 25,0 & 0,7 & 25,0 & 0,8 & 25,1 & 0,8 & 25,1 \\
2 & 0,9 & 25,4 & 0,9 & 25,4 & 1,0 & 25,4 & 0,7 & 25,1 & 0,8 & 25,1 & 1,6 & 25,0 & 0,7 & 25,2 & 0,6 & 25,2 & 0,6 & 25,2 \\
3 & 0,7 & 25,3 & 0,7 & 25,3 & 0,9 & 25,3 & 0,5 & 25,2 & 0,5 & 25,3 & 1,0 & 25,3 & 0,5 & 25,3 & 0,5 & 25,3 & 0,5 & 25,3 \\
4 & 0,6 & 25,3 & 0,6 & 25,3 & 0,6 & 25,3 & 0,4 & 25,3 & 0,4 & 25,3 & 0,5 & 25,4 & 0,4 & 25,3 & 0,4 & 25,3 & 0,4 & 25,3 \\
5 & 0,5 & 25,2 & 0,5 & 25,2 & 0,6 & 25,2 & 0,6 & 25,5 & 0,6 & 25,5 & 1,7 & 25,4 & 0,6 & 25,4 & 0,6 & 25,4 & 0,6 & 25,4 \\
6 & 0,7 & 25,0 & 0,8 & 25,1 & 0,8 & 24,9 & 0,4 & 25,3 & 0,6 & 25,3 & 2,5 & 25,3 & 0,6 & 25,2 & 0,6 & 25,3 & 0,6 & 25,3 \\
7 & 0,6 & 24,8 & 0,6 & 24,7 & 0,6 & 24,7 & 0,5 & 25,0 & 0,5 & 25,0 & 0,6 & 25,0 & 0,4 & 25,1 & 0,4 & 25,1 & 0,4 & 25,1 \\
8 & 0,7 & 25,1 & 0,7 & 25,0 & 0,7 & 25,0 & 0,5 & 25,1 & 0,6 & 25,0 & 0,6 & 25,0 & 0,5 & 25,1 & 0,5 & 25,0 & 0,5 & 25,0 \\
\hline
\end{tabular}

\section{Dados Biológicos}

Foram encontrados 2.071 (média: 9,74; desvio: 26,97; min: 1,00; máx: 308,00) larvas de braquiúros distribuídas em dez espécies da Infraordem Brachyura. A região do Molhe Oeste apresentou maior abundância com 960 larvas (média: 12,78; desvio: 40,05; min: 1,00; máx: 308,00) de oito espécies, seguido da região do Molhe Leste com 600 larvas (média: 8,45; desvio: 12,16; min: 1,00; máx: 47,00) de sete espécies e a região 
ARAÚjo, P. H. V. de; MUELBERT, J. H.; CALAZANS, D. K. de. Estudo do fluxo larval de braquiúros no canal de acesso ao estuário da Lagoa dos Patos, Rio Grande, Rio Grande do Sul, Brasil.

do Centro do Canal com 511 (média: 8,16; desvio: 20,11; min: 1,00; máx: 124,00) larvas de seis espécies.

A espécie Armases rubripes (Rathbun, 1897) foi a mais abundante deste estudo com mais de $50 \%$ das larvas coletados, seguido de Neohelice granulata (Dana, 1851) com mais de 30\%. As demais espécies como Arenaeus cribrarius (Lamarck, 1818), Hexapanopeus caribbaeus (Stimpson, 1871), Cyrtograpsus angulatus (Dana, 1851), as do gênero Pinnixa (White, 1846), Rhithropanopeus harrisii (Gould, 1841), Pachygrapsus gracilis (Saussure, 1858), Cyrtograpsus affinis (Dana, 1851) e Stenorhynchus seticornis (Herbst, 1788) obtiveram colaboração menor do que $3 \%$ de na composição da fauna braquiurológica da Lagoa dos Patos (Tabela 2).

Tabela 3 - Abundância (ind. $100 \mathrm{~m}^{-3}$ ), média, desvio padrão e frequência de ocorrência das espécies de braquiúros coletadas nas diversas fases e estágios de desenvolvimento larval no período de estudo.

\begin{tabular}{|c|c|c|c|c|c|c|}
\hline Família & Espécie & $\begin{array}{c}\text { Fase } \\
\text { Estágio }\end{array}$ & Abundância & Média & $\begin{array}{l}\text { Desvio } \\
\text { Padrão }\end{array}$ & $\begin{array}{l}\text { Frequência } \\
\text { de } \\
\text { Ocorrência }\end{array}$ \\
\hline \multirow{5}{*}{ Sesarmidae } & \multirow{5}{*}{$\begin{array}{l}\text { A. rubripes } \\
(A . r)\end{array}$} & Megalopa & 168,97 & 11,26 & 11,31 & 0,31 \\
\hline & & Zoé 1 & 3785,68 & 88,04 & 70,18 & 0,96 \\
\hline & & Zoé 2 & 259,99 & 10,40 & 8,42 & 0,52 \\
\hline & & Zoé 3 & 74,41 & 5,72 & 3,09 & 0,27 \\
\hline & & Zoé 4 & 3,99 & - & - & 0,02 \\
\hline \multirow{5}{*}{ Varunidae } & \multirow{3}{*}{$\begin{array}{c}\text { N. granulata } \\
(N . g)\end{array}$} & zoé 1 & 3532,14 & 100,92 & 289,23 & 0,73 \\
\hline & & Zoé 2 & 33,23 & 4,75 & 1,33 & 0,15 \\
\hline & & Zoé 3 & 18,31 & 4,58 & 1,29 & 0,08 \\
\hline & $\begin{array}{c}\text { C. angulatus } \\
\text { (C.a) }\end{array}$ & Zoé 1 & 49,21 & 8,20 & 6,04 & 0,13 \\
\hline & $\begin{array}{l}\text { C.affinis } \\
\text { (C.af) }\end{array}$ & Zoé 2 & 6,16 & - & - & 0,02 \\
\hline \multirow{2}{*}{ Grapsidae } & \multirow{2}{*}{$\begin{array}{l}\text { P. gracilis } \\
\text { (P.g) }\end{array}$} & Zoé 1 & 16,31 & 6,31 & 5,16 & 0,04 \\
\hline & & Zoé 3 & 3,70 & - & - & 0,02 \\
\hline Portunidae & $\begin{array}{l}\text { A. cribrarius } \\
\text { (A.C) }\end{array}$ & Megalopa & 433,62 & 14.37 & 27,79 & 0,40 \\
\hline \multirow{3}{*}{ Panopeidae } & \multirow{2}{*}{$\begin{array}{l}\text { H. caribeus } \\
(\text { H.C) }\end{array}$} & Zoé 1 & 66,30 & 4,42 & 1,96 & 0,31 \\
\hline & & Zoé 2 & 12,16 & 4,05 & 1,86 & 0,06 \\
\hline & $\begin{array}{l}\text { R. harrissi } \\
\quad(R . h)\end{array}$ & Zoé 1 & 6,82 & 3,41 & 0,74 & 0,04 \\
\hline \multirow{2}{*}{ Pinnotheroidea } & \multirow{2}{*}{$\begin{array}{c}\text { Pinnixa sp. } \\
(P)\end{array}$} & Zoé 1 & 28,74 & 5,75 & 3,74 & 0,10 \\
\hline & & Zoé 3 & 16,00 & - & - & 0,02 \\
\hline Inachidae & $\begin{array}{l}\text { S. stecornis } \\
\text { (S.S) }\end{array}$ & Zoé 1 & 3,07 & - & - & 0,02 \\
\hline
\end{tabular}

Na transversal I (Figura 3A) realizada no dia 04 de março de 2010 às 14 h30min apresentou larvas de cinco espécies, com abundância média de 54,71 ind.100 ${ }^{-3}$ (desvio padrão 64,49). A região Leste possuiu a maior abundância do que a região Oeste com mais larvas acumuladas na superfície. Não foram encontradas larvas de braquiúros 
ARAÚjO, P. H. V. de; MUELBERT, J. H.; CALAZANS, D. K. de. Estudo do fluxo larval de braquiúros no canal de acesso ao estuário da Lagoa dos Patos, Rio Grande, Rio Grande do Sul, Brasil..

região do Centro do Canal. A espécie $A$. rubripes correspondeu cerca de $60 \%$ das larvas, seguido de $N$. granulata com 23,7\%, A. cribrarius com 12,1\%, Pinnixa sp. com 2,6\% e $H$. caribeus com $1,7 \%$. O fluxo larval foi maior na região do Molhe Oeste com maior exportação pela superfície. (Figura 3A).

$\mathrm{Na}$ transversal II (Figura $3 \mathrm{~B}$ ) realizada às $17 \mathrm{~h} 30 \mathrm{~min}$ foram encontradas larvas de seis espécies, com abundância média de 17,80 ind.100 ${ }^{-3}$ (desvio padrão 26,99). A região do Molhe Leste possuiu maior abundância, seguido da região do Molhe Oeste e da região do Centro do Canal. As espécies se acumularam mais na superfície com $A$. rubripes representando $78,5 \%$ das larvas, seguido de $A$. cribrarius com $8,7 \%, N$. granulata com $8,3 \%, H$. caribeus com $2,5 \%, C$. angulatus com 1,1 e $R$. harrisii com $0,8 \%$. O fluxo larval foi maior na região do Molhe Leste, seguido das regiões Oeste e Centro do Canal, ocorrendo maior exportação pela superfície (Figura 3B).

Às 20h30min (Figura 3C) larvas de cinco espécies foram encontradas no Canal de Acesso com abundância média de 22,07 ind. $100 \mathrm{~m}^{-3}$ (desvio padrão 39,04). A região Leste possuiu a maior abundância, seguido da região Oeste e Centro do Canal. A espécie mais representativa foi $A$. rubripes com $76,9 \%$, seguido de $N$. granulata com $19,5 \%, H$. caribeus com $1,5 \%, A$. cribrarius com $1,1 \%$ e $C$. angulatus com apenas $1 \%$; com maior abundância no fundo. O fluxo larval foi maior na região do Molhe Oeste, seguido da região Molhe Leste e do Centro do Canal. Mesmo o estrato do fundo apresentando maior abundância, a maior exportação ocorreu na superfície (Figura 3C).

$\mathrm{Na}$ transversal seguinte (Figura 3D) às $23 \mathrm{~h} 30 \mathrm{~min}$ foram coletadas larvas de quatro espécies com abundância média de 24,62 ind. $100 \mathrm{~m}^{-3}$ (desvio padrão 38,16 ). A região do Molhe Oeste foi mais abundante seguido da região do Centro do Canal e a região do Molhe Leste. Na camada da superfície foi observada alta abundância das larvas, sendo a $A$. rubripes com $92 \%$, seguido de $A$. cribrarius com 4,3\%, N. granulata com $2 \%, A$. cribrarius com $1,7 \%$. O fluxo das larvas de braquiúros teve o mesmo comportamento da abundância. (Figura 3D).

$\mathrm{Na}$ Transversal V (Figura 3E) no dia 05 de março de 2010 às $02 \mathrm{~h} 30 \mathrm{~min}$, foi registrada a maior abundância larval com valor médio de 116,47 ind.100 ${ }^{-3}$ (desvio padrão 330,32 ) com larvas de sete espécies. A região do Molhe Oeste possuiu maior abundância, seguido da região do Molhe Leste e região do Centro do Canal. Neste perfil os indivíduos se concentraram mais no fundo, sendo a espécie mais representativa $N$. granulata com $81,4 \%$, seguida de $A$. rubripes com $16,4 \%$, Pinnixa sp. com $0,8 \%$, $A$. cribrarius com $0,7 \%, H$. caribeus com $0,5 \%$ e com apenas $0,1 \%$ as espécies $C$. angulatus e $P$. gracilis. O fluxo também teve o mesmo comportamento da abundância. (Figura 3E).

$\mathrm{Na}$ Transversal VI (Figura 3F) às 05h30min, foi observada abundância larval média de 33,44 ind.100 ${ }^{-3}$ (desvio padrão 39,24 ) distribuídas em larvas de oito espécies. A região do Molhe Leste possuiu maior abundância, seguido da região do Molhe Oeste e da região do Centro do Canal com as larvas se concentrando mais ao fundo. A espécie com maior percentual nesta transversal foi $A$. rubripes com $55,1 \%$, seguido de $N$. granulata com $28,5 \%, A$. cribrarius com $13,4 \%$, com apenas $1 \%$ as espécies $C$. angulatus e $P$. gracilis e, com, menos de $1 \%$ as espécies Pinnixa sp. e S. stecornis. A maior exportação foi na região do Molhe Oeste, seguido da região do Centro do Canal e região do Molhe Leste com maior exportação na camada do fundo (Figura 3F).

Às 08h30min (Figura 3G) a abundância larval média foi de 40,55 ind. $100 \mathrm{~m}^{-3}$ (desvio padrão 70,15 ) distribuídas em larvas de sete espécies. A região do Centro do Canal possuiu a maior abundância, seguido da região do Molhe Leste e da região do Molhe Oeste. As larvas estavam mais abundantes na camada da superfície com $A$. rubripes representando $71.3 \%$ das larvas, seguido $N$. granulata $24.4 \%$, C. angulatus com $2 \%, H$. caribeus com $1.2 \%$ e com menos de $1 \%$ as espécies $P$. gracilis, $R$. harrisii e Pinnixa sp. A região com maior fluxo foi a do Centro do Canal, seguido da região do Molhe Oeste e da região do Molhe Leste com maior exportação na superfície (Figura 3G).

$\mathrm{Na}$ última transversal (Figura $3 \mathrm{H}$ ) às 11h30min, a abundância média foi de 47,24 ind. $100 \mathrm{~m}^{-3}$ (desvio padrão 68,60 ) com larvas de cinco espécies. A região do Centro do 
ARAúJo, P. H. V. de; MUELBERT, J. H.; CALAZANS, D. K. de. Estudo do fluxo larval de braquiúros no canal de acesso ao estuário da Lagoa dos Patos, Rio Grande, Rio Grande do Sul, Brasil.

Canal apresentou a maior abundância, seguido da região do Molhe Leste e região do Molhe Oeste. A espécie mais representativa foi $A$. rubripes com $81.6 \%$, seguido de $N$. granulata $16,5 \%, H$. caribeus $1,0 \%$ e com porcentagem menor do que $1 \%$ as espécies $C$. affinis e $A$. cribrarius, sendo mais abundantes na camada da superfície. A região do Centro do Canal possuiu a maior exportação larval, seguido da região do Molhe Oeste e região do Molhe Leste. O fluxo nos estratos se comportou igual à abundância (Figura $3 \mathrm{H})$.

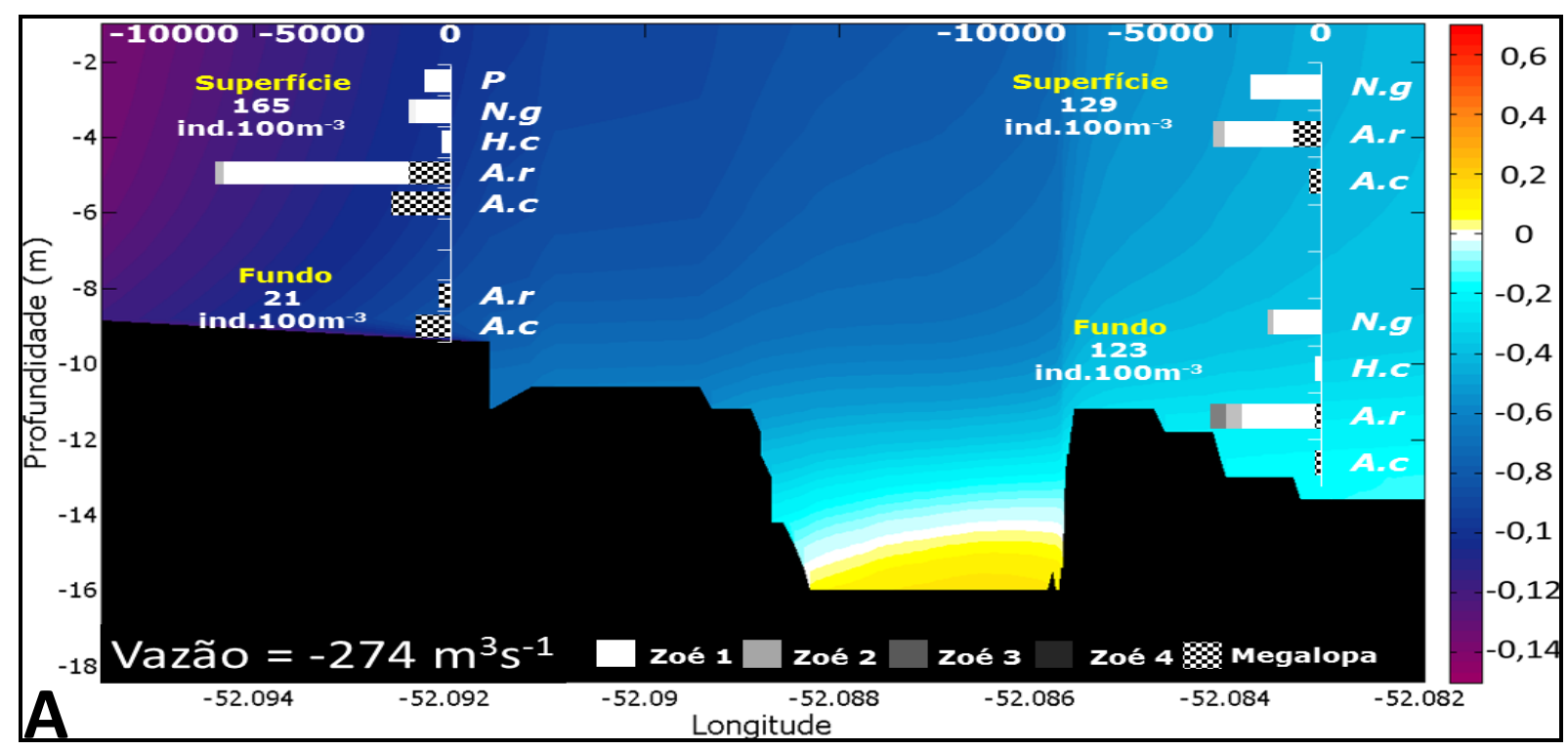


ARAúJO, P. H. V. de; MUELBERT, J. H.; CALAZANS, D. K. de. Estudo do fluxo larval de braquiúros no canal de acesso ao estuário da Lagoa dos Patos, Rio Grande, Rio Grande do Sul, Brasil..

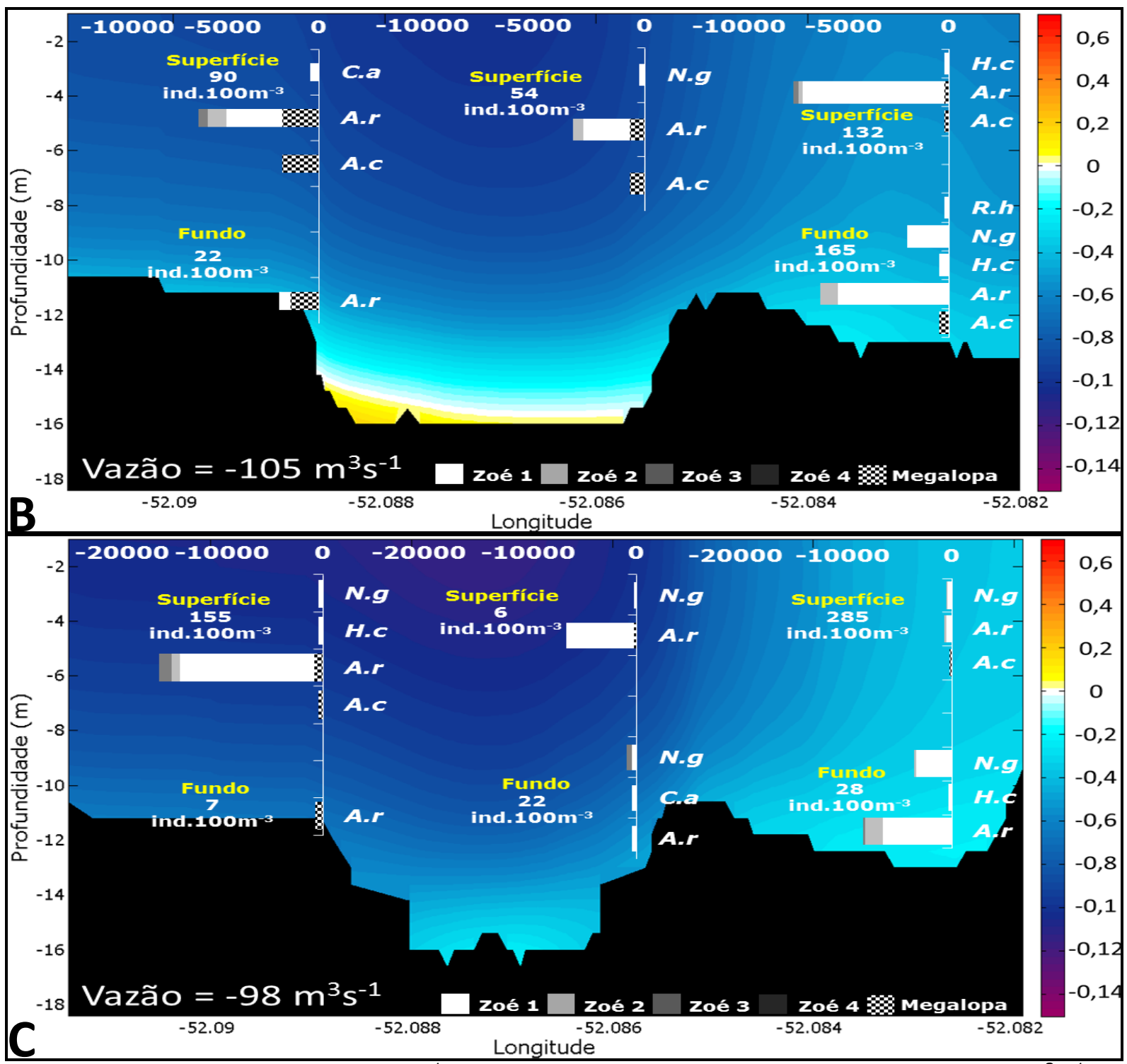

Figura 3: Perfil de velocidade $\left(\mathrm{ms}^{-1}\right)$, distribuição vertical do fluxo larval (ind.100 $\mathrm{m}^{-2} \mathrm{~s}^{-1}$ ) e abundância nos estratos. A) Transecto 1, B) Transecto 2 e C) Transecto 3. As siglas das espécies encontram-se na tabela 3.

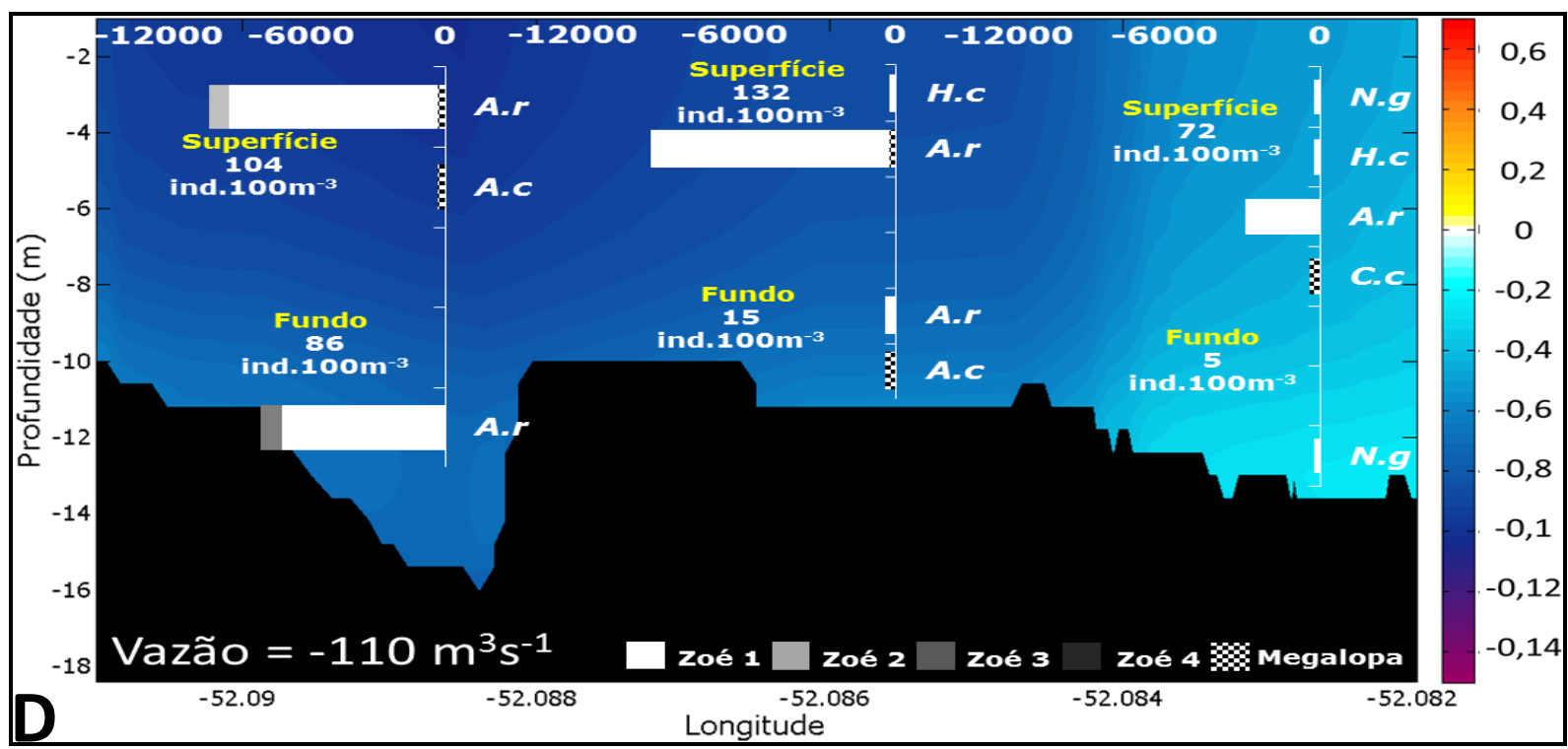


ARAúJo, P. H. V. de; MUELBERT, J. H.; CALAZANS, D. K. de. Estudo do fluxo larval de braquiúros no canal de acesso ao estuário da Lagoa dos Patos, Rio Grande, Rio Grande do Sul, Brasil.
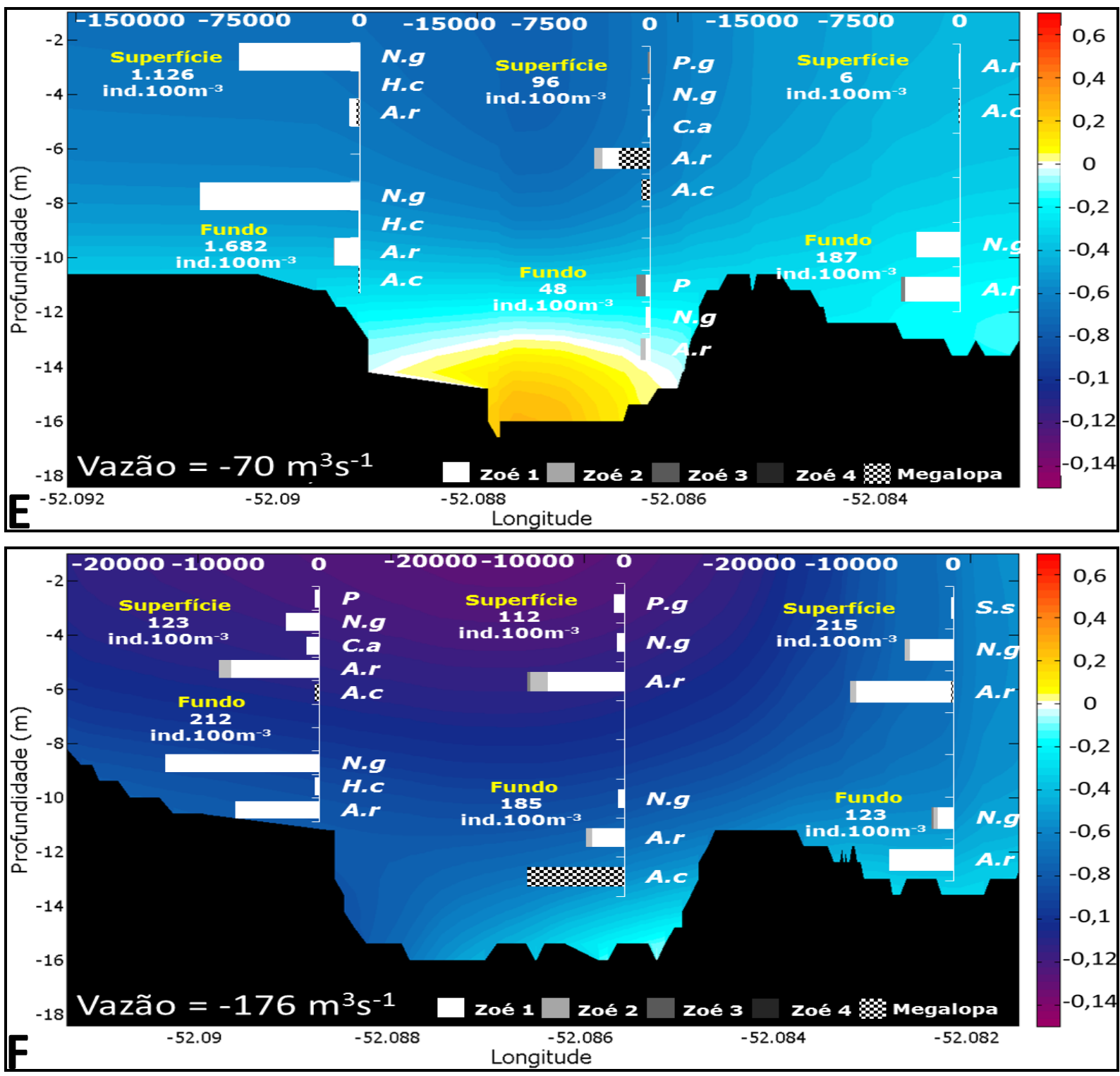

Figura 3 - Perfil de velocidade $\left(\mathrm{ms}^{-1}\right)$, distribuição vertical do fluxo larval (ind. $100 \mathrm{~m}^{-2} \mathrm{~s}^{-1}$ ) e abundância nos estratos. D) Transecto 4, E) Transecto 5 e F) Transecto 6. As siglas das espécies encontram-se na tabela 3. 

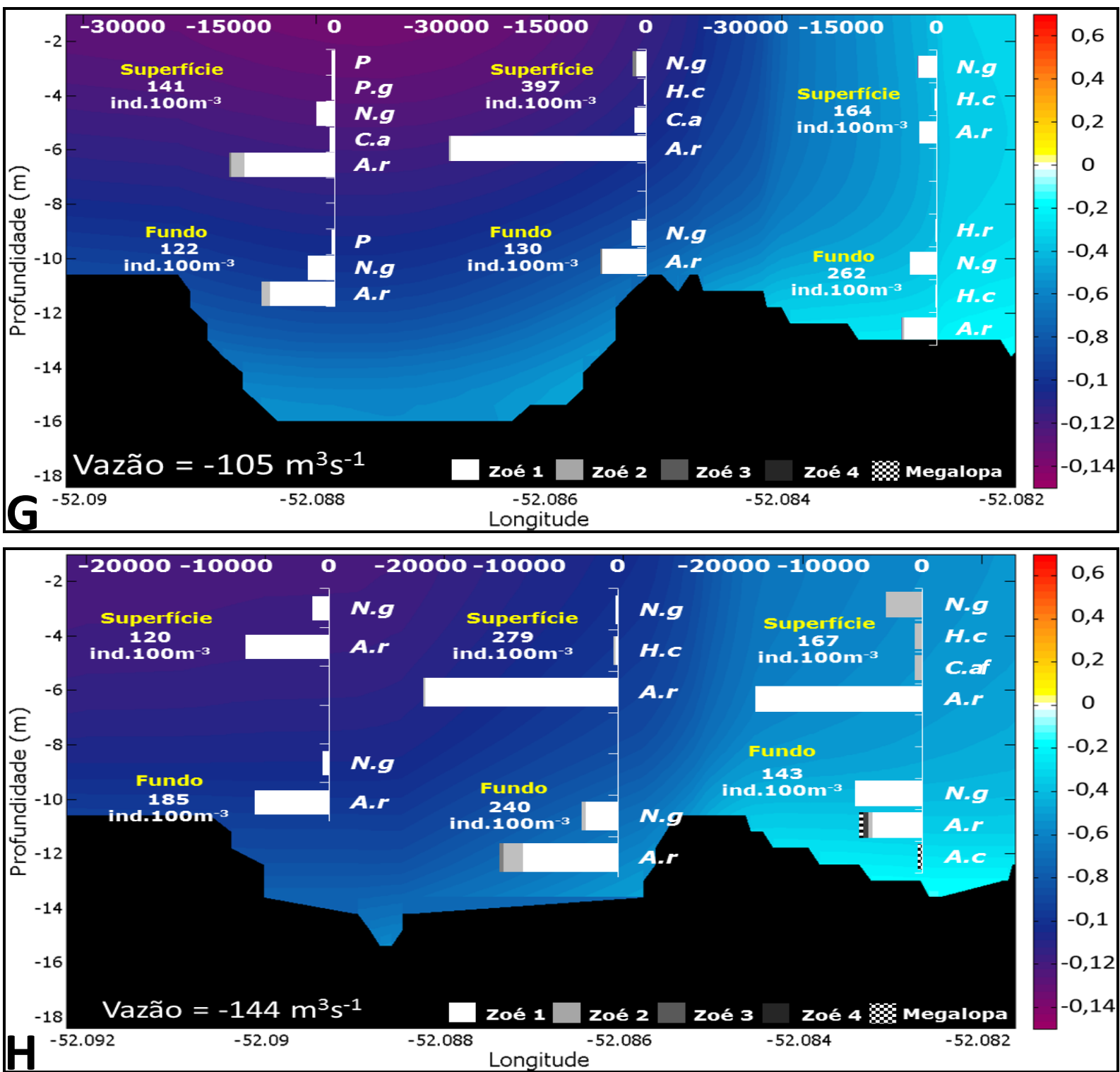

Figura 3 - Perfil de velocidade $\left(\mathrm{ms}^{-1}\right)$, distribuição vertical do fluxo larval (ind. $100 \mathrm{~m}^{-2} \mathrm{~s}^{-1}$ ) e abundância nos estratos. G) Transecto 7 e H) Transecto 8. As siglas das espécies encontram-se na tabela 3.

Foi registrada uma alta similaridade entre as transversais $(\approx 90 \%)$ (Figura $4 \mathrm{~A}$ ), em relação às espécies nas fases e estágios de desenvolvimento. Isto é devido à presença em todas as amostras das espécies $A$. cribrarius, $A$. rubripes, $N$. granulata e $H$. caribbeus nas diversas fases larvais. Em contrapartida pode-se considerar a presença três grupos, com similaridade de 53\%, explicado quanto ao comportamento do fluxo larval. O primeiro grupo é formado pelas quatro primeiras transversais, com baixos valores de fluxo; o segundo formado pelas três últimas transversais, com valores de fluxo moderados e; por fim o terceiro grupo que é composto apenas pela a transversal cinco, na qual mesmo tendo a menor vazão registrada neste estudo apresentou alto valor no fluxo larval.

Também foi registrada uma alta similaridade entre os pontos amostrados $(\approx 80 \%)$ (Figura 4B) em relação às espécies nas fases e estágios de desenvolvimento, no entanto pode se distinguir dois grupos numa similaridade de $57 \%$. O primeiro grupo com maiores diversidades e menores valores fluxos, composto pelas regiões de Centro do Canal $\left(1,212\right.$ nats.ind $\left.{ }^{-1}\right)$ e do Molhe Leste $\left(1,136\right.$ nats.ind $\left.^{-1}\right)$ e o segundo com menor diversidade e alto valor de fluxo composto pelo Molhe Oeste $\left(1,018\right.$ nats.ind $\left.^{-1}\right)$. 
ARAúJO, P. H. V. de; MUELBERT, J. H.; CALAZANS, D. K. de. Estudo do fluxo larval de braquiúros no canal de acesso ao estuário da Lagoa dos Patos, Rio Grande, Rio Grande do Sul, Brasil.

A Diversidade de Shannon apresentou comportamento bimodal, com maiores valores associado à presença da cunha salina. Um fluxo total de 623.630 ind.100 $\mathrm{m}^{-2} \mathrm{~s}^{-1}$ foi exportado para o oceano adjacente preferencialmente pela região do Molhe Oeste através da camada da superfície. De acordo com a correlação de Pearson entre a Diversidade de Shannon e a Vazão do Estuário $(0,69)$, revela que a força da vazão é capaz de transportar uma maior quantidade de espécies distintas para o oceano adjacente (Tabela 4). Já a correlação entre a Diversidade de Shannon e Fluxo Médio foi de $-0,59$.
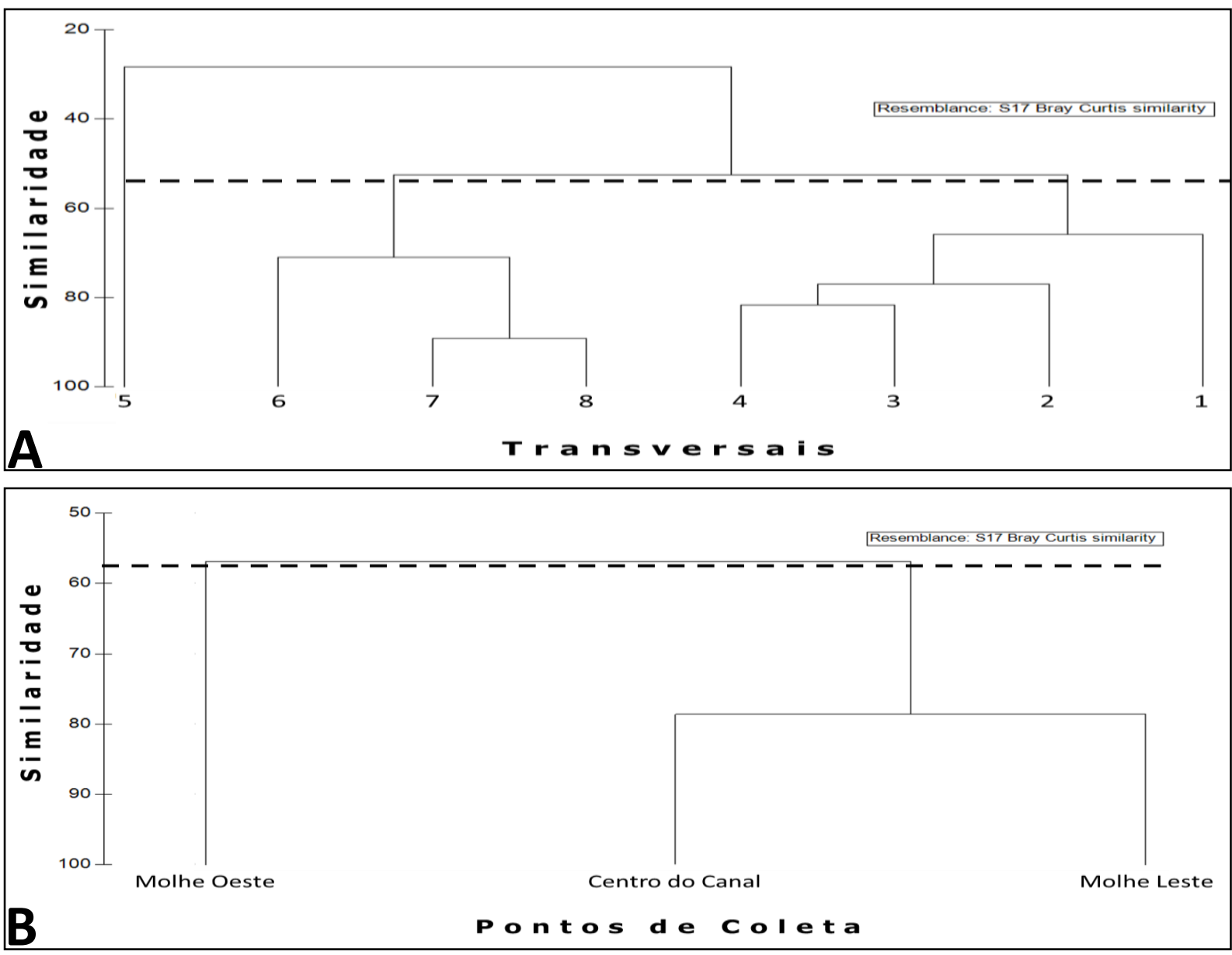

Figura 4: Diagrama de Agrupamento calculada pela similaridade de Bray-Curtis. A) Agrupamento entre as transversais e; B) Agrupamento entre os Pontos de Coleta.

Tabela 4 - Valores de Diversidade de Shannon $\left(\mathrm{H}^{\prime}\right)$ em nats.ind ${ }^{-1}$, Vazão $\left(\mathrm{m}^{3} \mathrm{~s}^{-1}\right)$, Fluxo Total (ind. $100 \mathrm{~m}^{-2} \mathrm{~s}^{-1}$ ), Fluxo Médio (ind. $100 \mathrm{~m}^{-2} \mathrm{~s}^{-1}$ ) e Desvio Padrão

\begin{tabular}{cccccc}
\hline Transversal & $\begin{array}{c}\text { Diversidade de } \\
\text { Shannon }\left(H^{\prime}\right)\end{array}$ & Vazão & Fluxo Total & Fluxo Médio & $\begin{array}{c}\text { Desvio } \\
\text { Padrão }\end{array}$ \\
\hline 1 & 1,673 & -274 & $26.284,18$ & 1.051 & 1.393 \\
\hline 2 & 1,382 & -105 & $31.950,91$ & 1.183 & 1.589 \\
3 & 1,232 & -98 & $39.609,75$ & 1.523 & 2.942 \\
4 & 0,640 & -110 & $32.098,02$ & 1.888 & 3.093 \\
5 & 0,690 & -70 & $223.488,10$ & 8.277 & 24.475 \\
6 & 1,370 & -176 & $89.648,30$ & 3.091 & 3.766 \\
7 & 0,965 & -105 & $91.333,78$ & 3.044 & 5.774 \\
8 & 0,803 & -144 & $89.216,71$ & 3.717 & 5.325 \\
\hline
\end{tabular}





\section{DISCUSSÃO}

Antes do período de estudo o estuário da Lagoa dos Patos estava sob influência de ventos do quadrante norte, como é comum durante o ano para esta região (Tomazelli, 1993) e com o nível da água acima de zero. No entanto durante o período de estudo houve uma diminuição no nível da lagoa que pode está associada às menores forças dos ventos nordestes na região (Möller et al., 2001). O transporte diferencial proposto por Gafrée (1927) e observado por Schmitt (2010), não foi observado neste estudo. Entretanto, pode-se observar uma inversão de correntes próxima ao fundo associadas à entrada de água costeira. Porém a salinidade foi inferior à média reportada para a região (Castello, 1985) e esses valores podem ser atribuídos as constantes descargas de água doce proveniente da bacia de drenagem. A temperatura manteve-se constante e com valor médio semelhante ao reportado para a região no verão (Möller \& Castaing, 1999).

A densidade e o fluxo das larvas de braquiúros apresentaram grandes variações, entretanto estes valores foram aumentando durante o período de estudo. As larvas de braquiúros comumente entram e saem do estuário através de correntes de superfície e de fundo (Vieira, 2006), no entanto devido às condições oceanográficas físicas registradas neste estudo, as larvas encontraram-se constantemente sendo exportadas para o oceano adjacente. Com grande intensidade nas proximidades do Molhe Oeste e maiores valores na camada da superfície por processo "offshore" (Shanks, 1995), como também foi observado no estudo na Carolina do Sul por Christy \& Stancyk (1982) e na baia de Guanabara (Fernandes et al., 2002).

As espécies com maiores abundâncias e fluxos foram os grapsideos $A$. rubripes e $N$. granulata. Estas larvas apresentaram alta abundância larval, representando mais de $90 \%$ das larvas coletados. Isto é devido a maior adaptabilidade deste grupo entre os braquiúros, já que os adultos colonizam diferentes habitats, podendo ser encontrados desde o ambiente marinho, passando pela região entremarés, estuário, água doce e associado a bromeliáceas (Hartnoll, 1964; Melo, 1996; Abele \& Means, 1977; Abele, 1992; Diesel, 1992; Anger, 1995; Diesel \& Horst, 1995; Teixeira \& Sá, 1998). Os grapsídeos foram bem representativos neste estudo, assim como foi verificado na Baía de Guanabara (Fernandes et al., 2002) e no estuário do Rio Jaguaribe destacando-se $A$. rubripes e $P$. gracilis (Silva-Falcão et al., 2007).

A espécie Armases rubripes compôs mais de $50 \%$ da densidade das larvas coletadas nesta região, estando presente na maioria das amostras de arrasto. A exportação das larvas desta espécie foi mais eficaz pela superfície próximo ao Molhe Oeste. Segundo Montú et al. (1990) o desenvolvimento larval desta espécie é composto por cinco estágios de zoés e um de megalopa. Entretanto só foram encontradas larvas nos três primeiros estágios. A ausência dos estágios seguintes pode está associada à necessidade de altas salinidades para completar sua metamorfose (Luppi et al., 2003). As megalopas possuíram maiores taxas de exportação durante a presença do pico na cunha salina mais evidente, a qual possuía camada mais espessa devido à diminuição da força dos ventos. Provavelmente essas larvas vieram através da água de fundo e redistribuídos na coluna d'água por processos de mistura, sendo desta forma levados de volta para região costeira pela camada de superfície. O fluxo de zoé I aumentou durante o período de estudo, no entanto foi possível observar uma exportação em ordem ontogenética entre larvas de zoé II e zoé III. As larvas em zoé II apresentaram maior taxa de exportação logo após a presença da cunha salina enquanto que as larvas em zoé III foram exportadas bem depois da presença da cunha salina, apresentando uma possível retenção larval ou causando retardo na exportação. Esta prioridade no fluxo de zoé I pode ser devido a menor capacidade osmorreguladora das larvas neste estágio, pois estas espécies só completam suas metamorfoses em temperaturas e salinidades altas (Luppi et al., 2003). Com esse alto fluxo para o oceano adjacente, as larvas de $A$. rubripes, são capazes de atravessar a barreira do Rio de La Plata e chegar à costa da Argentina durante a diminuição da descarga de água doce deste mesmo rio (Luppi et al., 2003). Armases rubripes é um caranguejo de pequeno porte encontrado comumente na

1- Instituto de Oceanografia - Universidade Federal do Rio Grande - FURG. Av. Itália Km 8, Caixa Postal 474, Rio Grande - RS - Brasil. 2 - Laboratório de Ecologia do Ictioplânton. 3 - Laboratório de Crustáceos Decápodos. 
ARAÚJO, P. H. V. de; MUELBERT, J. H.; CALAZANS, D. K. de. Estudo do fluxo larval de braquiúros no canal de acesso ao estuário da Lagoa dos Patos, Rio Grande, Rio Grande do Sul, Brasil..

região sul do Brasil em pântanos salgados, marismas, habitando raízes e bases dos caules da vegetação halófita de gramíneas, fissuras e cavidades do substrato (Capítoli et al., 1977). As fêmeas desta espécie se reproduzem da primavera ao outono na Ilha do Farol (Kowalczuk \& Masunari, 2000), com pico reprodutivo em março na Baia de Sepetiba (Lima et al., 2006). Na região estuarina da Lagoa dos Patos possuem em média 3.790 ovos (Capitoli et al., 1977) e quando estudada em laboratório apresentou elevado valor de fecundidade em relação a outros Grapsoidea (Lima, 2007).

Não foram encontrados larvas de Neohelice granulata na fase de megalopa, no entanto foi a segunda espécie com maior densidade de zoés. Dos quatro estágios de zoés reportados para esta espécie (Rieger \& Santos, 2001), só foram encontradas as três primeiras. O estágio de zoé I foi o mais representativo com $98 \%$ das larvas, ocorrendo poucas em zoé II e III. Larvas de Zoé I apresentaram maior taxa de exportação na região do Molhe Oeste próximo ao fundo, quando a cunha salina estava intensa e espessa, com pouca ação dos ventos. Sendo este fluxo maior nas ultimas horas deste estudo. Os estágios de zoé II e III tiveram maior exportação nas regiões de menores velocidades, como a região do Molhe Leste no estrato do fundo, com picos de fluxo a partir da presença da cunha salina. O estágio de zoé III teve maior fluxo nas ultimas horas de estudo. Esta espécie estuaria é encontrada em pântanos e manguezais da Costa do Atlântico Sul, do Rio de Janeiro (Brasil) à Patagônia (Argentina) (Melo, 1996), sendo a mais abundante da família Grapsidea no estuário da Lagoa dos Patos (Rieger \& Santos, 2001). As fêmeas desta espécie que habitam a Laguna Mar Chiquita tem o pico de atividade reprodutiva em março (Ituarte et al., 2004) e possuem fecundidade média em torno de 54.000 ovos (Silva et al., 2009). Na baia de Baia de Samborombón a fecundidade média é menor com 30.000 ovos (César et al., 2007). De acordo com Cazorla (1987) N. granulata tem um papel muito importante no estuário de Bahía Blanca como alimento para peixes de interesse comercial que se reproduzem e se desenvolvem nesta baia.

Os outros Grapsoídeos como C. angulatus e $C$. affinis e $P$. gracilis tiveram baixa representatividade relação às outras espécies. As duas últimas também foram raras no estudo de Vieira (2006), sendo encontradas apenas no verão. Entretanto, para este mesmo autor, C. angulatus foi abundante para o verão. O fluxo de exportação destas três espécies foi observado apenas nas últimas horas de estudo, ocorrendo pela superfície nas proximidades do Molhe Oeste, corroborando para o estudo de Silva-Falcão et al. (2007) no estuário do Rio Jaguaribe, a dispersão de espécies da família Grapsidae para áreas costeiras.

A única espécie coletada da Portunidae foi Arenaus cribrarius. Este portunideo é popularmente conhecido como siri-chita é residente da zona de surf de praias arenosas, permanecendo enterrado na maioria das vezes (Pinheiro \& Frasozo, 2002). Segundo Stuck \& Truesdale (1988) A. cribrarius possui oito estágios de zoés e um de megalopa, no entanto foi a espécie que apresentou maior número de megalopas neste estudo, corroborando para o trabalho de Vieira (2006) na Lagoa dos Patos. A exportação destas megalopas foi mais intenso próximo à região do Molhe Oeste e pela superfície com pico na presença da cunha salina mais espessa, que está associada às menores forças dos ventos. A ausência de zoés de $A$. cribrarius neste estudo também foi observada por Vieira (2006) para a Lagoa dos Patos, o qual atribui que isto é o comportamento dos adultos desta espécie, pois habitam a região costeira adjacente e não estão presentes no interior do estuário. Segundo Epifanio \& Dittel (1984) as zoés de portunideos preferem as altas salinidades para completar seu desenvolvimento larval e em condições de laboratório se desenvolvem em água com salinidade superior a 25 (Stuck \& Truesdale, 1988). Desta forma acredita-se que as zoés estejam se desenvolvendo no oceano adjacente e que as megalopas coletadas no interior do canal tenham sido arrastadas pela corrente de fundo oriundas do oceano para dentro do estuário, redistribuídas na coluna d'água por processos de mistura e retornaram ao oceano adjacente pela camada de superfície.

Foi observada pela primeira vez na região a presença do Caranguejo-Aranha, Stenorhynchus seticornis da Família Inachidae. Com apenas dois estágios de zoé e uma 
ARAÚjo, P. H. V. de; MUELBERT, J. H.; CALAZANS, D. K. de. Estudo do fluxo larval de braquiúros no canal de acesso ao estuário da Lagoa dos Patos, Rio Grande, Rio Grande do Sul, Brasil.

de megalopa (Pinheiro et al., 1994; Rhyne et al., 2003; Mendes \& Valença, 2008), esta espécie apareceu em apenas uma amostra como zoé I com fluxo em direção ao oceano adjacente pela superfície nas proximidades do Molhe Leste, sendo a primeira vez que é observada na região de estudo. Os adultos desta espécie sofrem uma alta captura em recifes de corais (Gasparini et al., 2004), pois possuem valor comercial para os apreciadores de aquariofilia, no entanto devido ao curto ciclo larval é um candidato promissor para a aquicultura ornamental (Mendes \& Valença, 2008).

Vieira (2006) na Lagoa dos Patos e Silva-Falcão (2007) no estuário do Rio Jaguaribe encontraram zoés nos cinco estágios de desenvolvimento (Bousquette, 1980; Lima et al., 2006) de Pinnixa sp. As zoés de Pinnixa sp. registrou alta abundância na Lagoa dos Patos e ocorreram em todas as localidades da lagoa (Vieira, 2006). Neste presente estudo as larvas Pinnixa sp. foram pouco abundantes, no entanto teve maior ocorrência na presença da maior cunha salina, tal como ocorreu no estuário do Rio Jaguaribe em Pernambuco (Silva-Falcão et al., 2007). Isto pode ser devido à entrada das larvas pela cunha salina, já que são espécies costeiras e por conta da turbulência das correntes estavam retornando à costa pela superfície. A baixa abundância, assim como a não ocorrência dos demais estágios de desenvolvimento pode está atribuída ao constate regime de vazante hidrológico da lagoa associado à força e direção dos ventos. As zoés desta espécie, mesmo habitando a região costeira adjacente, podem se desenvolver no estuário da Lagoa dos Patos retornando através de corrente vazante na fase Megalopa para a região costeira adjacente aonde irão se assentar e mudar para a fase juvenil (Vieira, 2006).

Dentre as espécies de Panopeidae, Hexaponopeus caribeus foi mais abundante do que Rhithropanopeus harrisii. Segundo Vieira \& Rieger (2004) H. caribbeus apresenta quatro estágios de zoés e uma de megalopa, no entanto para este estudo só foram encontradas larvas nos estágios zoé I e II, com maior abundância de zoé I. Não foram encontradas larvas próximas ao fundo no Centro do Canal, entretanto os maiores valores de exportação foram observados na superfície nas proximidades do Molhe Oeste. A espécie de $R$. harrisii possui mecanismo de retenção larval em estuários (Cronin, 1982) e é considerada uma espécie invasora para a região de estudo (Tavares \& Mendonça, 2004), possui cinco estágios de desenvolvimento de zoé e uma de megalopa (Connolly, 1925), no entanto foram identificadas apenas larvas em zoé I. Este baixo fluxo para o oceano adjacente provavelmente está relacionado a uma retenção das larvas, no alto estuário, próximo ao habitat dos adultos. Essa retenção sugere que estas larvas são muito tolerantes à salinidade (Sandifer, 1973; Sandifer, 1975; Cronin, 1982; Goncalves et al., 1995; Vieira, 2006), visto que esta espécie possui uma boa osmoregulação (Forward, 2009) além de se metamorfosear mais rapidamente em águas estuarinas de baixa salinidade (Fitzgerald et al., 1998).

Embora a região nas proximidades do Molhe Oeste tenha apresentado os maiores fluxos larvais, possui a menor diversidade de espécies registrada no Canal de Acesso. 0 inverso ocorreu para o Canal de Acesso e proximidades do Molhe Leste, indicando serem regiões de possível retenção larval, pois são regiões com velocidades de correntes menos intensas.

Não foi observada grande heterogeneidade vertical da fauna braquiurológica na coluna d'água no interior do Canal de Acesso a Lagoa dos Patos durante as horas. Evidenciando a ausência da migração vertical, que pode está associada ao regime hidrológico de vazante pelo qual a lagoa se encontrava. Como praticamente toda a coluna d'água estava em vazante, as larvas não teriam necessidade de migrar para a camada de superfície para serem exportadas para o oceano adjacente.

Devido ao baixo número de horas de coleta não foram encontradas correlações significativas entre a diversidade em relação à vazão líquida e ao fluxo médio das larvas de braquiúros. Entretanto as inversões de valores pode indicar que outras espécies tenham mecanismos de retenção larval e/ou a diminuição do fluxo possibilita o agrupamento de mais espécies. 
ARAúJO, P. H. V. de; MUELBERT, J. H.; CALAZANS, D. K. de. Estudo do fluxo larval de braquiúros no canal de acesso ao estuário da Lagoa dos Patos, Rio Grande, Rio Grande do Sul, Brasil..

O elevado número de larvas coletadas no primeiro estágio larval, também observado no Rio Jaguaribe por Silva-Falcão et al. (2007), deve-se a ocorrência de um grande número de espécies que adotam a estratégia reprodutiva de sincronizar suas atividades de desova com os meses de temperatura mais elevada (Montu, 1980). Reforçando o importante papel de berçário das regiões estuarinas como a Lagoa dos Patos (González-Gordillo \& Rodriguez, 2003), tendo o papel primordial na manutenção das espécies da fauna braquiurológica da região. Transportando-as através do regime hidrológico para as regiões onde melhor se desenvolvem até o seu assentamento no substrato.

As espécies $A$. cribrarius, $A$. ribripes, $N$. granulata e Pinnixa sp. tiveram maior exportação associada a presença da cunha salina, o que leva a crer que essas larvas estejam em constante entrada e saída no Canal de Acesso através das forças das correntes de fundo e superfície. Este comportamento pode ser em função da alimentação já que regiões estuarinas possuem alta produtividade (Loebmann et al., 2008).

\section{CONCLUSÃO}

O Canal de Acesso à Lagoa dos Patos é uma região vital para o transporte de espécies de braquiúros, pois suas larvas utilizam dos recursos físicos como ventos, descarga de água doce e marés para potencializar suas metamorfoses, alimentação e dispersão. As espécies Armases rubripes e Neohelice granulata, assim como em outras regiões do Brasil representaram alta abundância por estar no verão em época reprodutiva e consequentemente alto fluxo larval em direção ao oceano adjacente. Também foi observado o primeiro registro de zoés da espécie Stenorhynchus seticornis no interior do Estuário da Lagoa dos Patos.

Os picos de fluxos larvais de exportação estão associados a presença da cunha salina no estuário, permitindo a entrada de larvas meroplanctônicos que se encontram na região costeira. As maiores velocidades de correntes encontram-se na superfície das proximidades do Molhe Oeste e são responsáveis pela grande parte do fluxo de larvas do canal. As baixas velocidades de correntes nas regiões próximas ao Centro do Canal e Molhe Leste contribuem para que as lavas sejam exportadas de uma forma mais lenta. A espécie Armases rubripes apresentou exportação de acordo com o desenvolvimento ontogenético, entretanto a espécie invasora Rhithropanopeus harrisii apresentou mecanismo de retenção larval no estuário da Lagoa dos Patos.

De acordo com as características físicas atribuídas ao regime de ventos e de descarga, a Lagoa dos Patos teria o papel de enriquecer a região costeira adjacente, sendo lavada continuamente. Mas em que momento seria o retorno desses indivíduos em altas densidades na lagoa para o enriquecimento desse sistema? Este processo ocorre continuamente através do transporte de organismos pelas correntes de fundo e de superfície? Como esse ambiente se sustenta biologicamente?

Devido ao curto período observacional e para responder estas questões é necessária a continuação desse estudo incluindo mais espécies planctônicas utilizando o ADCP numa periodicidade regular englobando todas as estações do ano. Desta forma será possível confirmar as breves conclusões deste estudo e compreender a ecologia planctônica no Canal de Acesso à Lagoa dos Patos.

\section{AGRADECIMENTOS}

Ao Programa de Pós-Graduação em Oceanografia Biológica - Instituto Oceanográfico - Universidade Federal do Rio Grande (FURG) e ao Conselho Nacional de Desenvolvimento Científico e Tecnológico (CNPq), pelo auxílio financeiro que possibilitou a realização deste estudo.

\section{REFERÊNCIAS}

ABELE, L.G. Anote on the Brazialian bromeliad crab (Crustacea, Grapsidae). Arq. Cien. Mar., Fortaleza, v. 2, n. 12, p.123-126. 1972. 
ARAúJO, P. H. V. de; MUELBERT, J. H.; CALAZANS, D. K. de. Estudo do fluxo larval de braquiúros no canal de acesso ao estuário da Lagoa dos Patos, Rio Grande, Rio Grande do Sul, Brasil.

ABELE, L.G; MEANS, D.B. Sesarma javirsi and Sesarma cookei: Montane terrestrial grapsid crabs in Jamaica. Crustaceana, Leiden, v. 1, n. 32, p.91-93. 1977.

ANDRADE, M.M. Estrutura das correntes na área do canal de acesso à Lagoa dos Patos: curvas de vazão. 2010. 41f. Monografia (Graduação em Oceanologia) - Instituto de Oceanografia. Universidade Federal do Rio Grande.

ANGER, K. The conquest of freshwater and land by marine crabs: adaptations in lifehistory patterns and larval bioenergetics. J. Exp. Mar. Biol. Ecol., Elsevier, n. 193, p.119145. 1995.

BONILHA, L.E. Modelo ecológico da coluna d'água do estuário da Lagoa dos Patos (RSBrasil) MELP: Uma abordagem sistêmica e integrada. 1996. 274p. Dissertação (Mestrado Oceanografia Biológica) - Instituto de Oceanografia. Universidade Federal do Rio Grande.

BOUSQUETTE, G.D. The larval development of Pinnixa longipes (lockington, 1877) (brachyura: pinnotheridae), reared in the laboratory. Biol Bull, n. 159, p.592-605. 1980.

BRAGA, MFS, KRUSCHE, N. Padrão de Ventos em Rio Grande, RS, no período de 1992 a 1995. Atlântica, Rio Grande, v. 22, p. 27-40. 2000.

CADDY, J.F. Recent developments in research and management for wild stocks of bivalves and gastropods. In: Caddy, J. F. (Ed.). Marine invertebrate fishery: Their assessment and management. John Wiley e Sons, London, UK, 1989, p. 665 - 699.

CALAZANS, D.K. Morphology, abundance and distribution of larval phases of two Sergestids in the Southern Brasilian Coast. Nauplius, v 2, p. 75 - 86. 1994.

CAPÍTOLI, R.R; BENVENUTI, C.E; GIANUCA, N.M. Ocorrência e observações bioecológicas do caranguejo Metasesarma rubripes (Rathbun) na região estuarina da Lagoa dos Patos. Atlântica, Rio Grande, v. 1, n. 2, p.50-62. 1977.

CASTELLO, J.P. La Ecologia de Los Consumidores Del Estuario de Lagoa dos Patos, Brasil. In Fish Community Ecology In Estuaries And Coastal Lagoons: Towards An Ecosystem Integration Ed. Por A.Yanez-Arancibia. Universidade Nac Aut Mex Chap, México, v. 17, 1985 , p. 383-406.

CASTELLO, J.P. Sinopsis on the reproductive biology and early life history of Engraulis anchoita, and related environmental conditions in brazilian waters. In: IOC Workshop on Sardine/Anchovy Recruiment Project (SARP) in the Southwest Atlantic Workshop Rep. No65, 1990, p $19-24$.

CASTELLO, P.J; MÖLLER, O.O. On the relationship between rainfall and shrimp production in the estuary of Patos Lagoon (Rio Grande do Sul, Brasil). Atlântica, v 3, p. 67-74. 1978.

CAZORLA, A.L. Contribución al conocimiento de la ictiofauna marina del área de Bahía Blanca. La Plata. 224f. 1987. Tese (Doutorado Ciencias Naturales) - Facultad de Ciencias Naturales y Museo. Universidad Nacional de La Plata.

CESAR, I.I; ARMENDARIZ, L.C; BECERRA, R.V. Fecundity of Uca uruguayensis and Chasmagnathus granulatus (Decapoda, Brachyura) from the "Refugio de Vida Silvestre" Bahía Samborombón, Argentina. Braz. J. Biol. 2007, v.67, n.4, p. 749-753. 2007.

CHRISTY, J.H; STANCYK, S.E. Timing of larval production and flux of invertebrate larvae in a well-mixed estuary In: Kennedy 5 (ed) Estuarine Comparisons. Academic Press, New York, 1982, p 489-503.

CLOSS, D. New observations on the ecological subdivision of the Patos Lagoon in southern Brazil. Bol. Inst. Ciên. Nat., UFRGS, Porto Alegre/RS. 35. 1966.

CONNOLLY, C.J. The larval stages and megalops of Rhithropanopeus harrisii (Gould). Contrib. Canad. Biol. 2(2): 329-334. 1925.

CRONIN, T.W. Estuarine retention of larvae of the crab Rhithropanopeus harrisii. Estuar. Coast. Shelf Sci., n. 15, p.207-220. 1982. 
ARAúJO, P. H. V. de; MUELBERT, J. H.; CALAZANS, D. K. de. Estudo do fluxo larval de braquiúros no canal de acesso ao estuário da Lagoa dos Patos, Rio Grande, Rio Grande do Sul, Brasil..

DIESEL, R. Maternal care in the bromeliad crab, Metapaulias depressus: protection of larvae from predation by Danselfly nynphs. Anim. Behav., London, n. 43, p.308-812. 1992.

DIESEL, R; HORST, D. Breeding in a snail shell: ecology and biology of the Jamaican montane crab Sesarma javirsi (Decapoda: Grapsidae). J. Crust. Biol., Lawrence, n. 15, p.179-195. 1995.

DITTEL, A.I; EPIFANIO, C.E; LIZANO, O. Flux of crab larvae in a mangrove creek in the Gulf of Nicoya, Costa Rica. Estuar. Coast. Shelf Sci., n. 32, p.129-140. 1991.

EPIFANIO, C.E; DITTEL, A.I. Seasonal abundance of brachyuran crab larvae in a tropical estuary: Gulf of Nicoya, Costa Rica, Central America. Estuaries,v 7, n 4B, p. 501-505. 1984.

EPIFANIO, C.E; VALENTI, C.C; PEMBROKE, A.E. Dispersal and recruitment of blue crab larvae in Delaware Bay, USA. Est. Coast. Shelf. Sci., V. 18, p. 1-12. 1984.

ESTEVES, FA. Fundamentos de Limnologia. $2^{\circ}$ ed. Rio de Janeiro. Interciência, 1998, 602 p.

FERNANDES, L.D.A; BONECKER, S.L.C. Dynamic of decapod crustacean larvae on the entrance of Guanabara bay. Braz. arch. biol. technol. V 45, n.4, pp. 491-498. 2002.

FITZGERALD, T.P; FORWARD JR, R.B; TANKERSLEY, R.A. Metamorphosis of the estuarine crab Rhithropanopeus harrisii: effect of water type and adult odor. Mar. Ecol. Prog. Ser., n. 165, p.217-223. 1998.

FORWARD JR, R.B. Larval Biology of the Crab Rhithropanopeus harrisii (Gould): A Synthesis. Biol. Bull., v. 3, n. 216, p.243-256. 2009.

FORWARD JR, R.B; LOHMANN, K; CRONIN, T.W. Rhythms in larval release by an estuarine crab (Rhithropanopeus harrisii). Biology Bulletin 163: 287-300. 1982.

FREIRE, A.S. Dispersão larval do Caranguejo uçá Ucides cordatus (L.1763) em manguezais da Baía de Paranaguá, PR, Brasil. 67f, 1998. Doutorado em Oceanografia (Oceanografia Biológica) Universidade de São Paulo, USP, Brasil.

GAFFRÉE, C.L. Relatório sobre medições de correntes. Relatório apresentado ao Inspetor Federal de Portos, Rios e Canais, Rio Grande, RS. Rio Grande. 1927.

GASPARINI, J.L; FLOETER, S.R; FERREIRA, C.E.L; SAZIMA, I. Marine ornamental trade in Brazil. Biodiversity and Conservation v 14, p.2883-2899. 2005.

GONÇALVES, F; RIBEIRO, R; SOARES, A.M.V.M. Rhithropanopeus harrisii (Gould), an American crab in the estuary of the Mondego River, Portugal. J. Crust. Biol., n. 15, p.756-762. 1985.

GONZÁLEZ-GORDILLO, J.I; RODRIGUEZ, A. Comparative seasonal and spatial distribution of decapod larvae assemblages in three coastal zones off the south-western Iberian Peninsula. Acta Oecologica, v 24, n 1, p. 219-233. 2003.

HAIMOVICI, M. Present state and perspectives for the southern Brazil shelf demersal fisheries. Fish. Manage. Ecol., v 5, n 4, 277-290. 1998.

HARTNOLL, R.G. The freshwater grapsid crabs of Jamaican. Proc. Linn. Soc. Lond., London, v. 2, n. 175, p.145-169. 1964.

HENDRICKX, M.E. Checklist of brachyuran crabs (Crustacea: Decapoda) from the eastern tropical Pacific. Bull de L'Institut R. des Sci. Nat. de Bel.: Biologie, n. 65, p.125-150. 1995.

HERZ, R. Circulação das águas de superfície da Lagoa dos Patos. 340f. 1977. São Paulo, Tese (Doutorado em Oceanografia) - Faculdade de Filosofia, Letras e Ciências Humanas Universidade de São Paulo. 
ARAúJO, P. H. V. de; MUELBERT, J. H.; CALAZANS, D. K. de. Estudo do fluxo larval de braquiúros no canal de acesso ao estuário da Lagoa dos Patos, Rio Grande, Rio Grande do Sul, Brasil.

ITUARTE, R.B; SPIVAK, E; LUPPI, T. Female reproductive cycle of the Southwestern Atlantic estuarine crab Chasmagnatus granulatus (Brachyura: Grapsoidea: Varunidae). Sci. Mar., v 68, p. 127-137. 2004.

KJERFVE, B. Comparative oceanography of coastal lagoons. In: Estuarine Variability. Ed. D. A. Wolfe. 1986, 63p.

KOETTKER, A.G; SUMIDA, P.Y.G; LOPES, R.M; FREIRE, A.S. Illustrade key the identification of known zoeal stages of Brachyura (Crustacea: Decapoda) species form the tropical and subtropical Southwest Atlanctic. Zootaxa 3204: P. 1-19. 2012.

KOWALCZUK, V.G.L; MASUNARI, S. Estrutura populacional de Armases angustipes (Dana, 1852) (Decapoda, Brachyura, Grapsidae) da Ilha do Farol, Matinhos, Paraná. Rev bras. Zool. v 17, n 1, p.1-16, 2000.

LEVIN, L.A. Recent progress in understanding larval dispersal: new directions and digressions. Int. Comp. Biol. N46, p. 282-297, 2006.

LIMA, G.V. Bioecologia do Caranguejo Armases rubripes (Rathbun, 1897) (Crustacea, Brachyura, Sesarmidae) na Baía de Sepetiba, RJ. Seropédica, 201f. 2007. Tese (Doutorado em Biologia Animal) - Instituto de Biologia. Universidade Federal Rural do Rio de Janeiro.

LIMA, G.V; OSHIRO, L.M.Y, SOARES, M.R.S. Reproductive biology of the sesarmid crab Armases rubripes (Decapoda, Brachyura) from an estuarine area of the Sahy River, Sepetiba Bay Rio de Janeiro, Brazil. Iheringia. Sér. Zool., Porto Alegre, v. 1, n. 96, p.4752. 2006.

LOEBMANN, D; VIEIRA, J.P; BEMVENUTI, M.A; ASTARLOA, J.M.D; COUSSEAU, M.B; FIGUEROA, D. Composição e abundância da icitofauna de duas laguinas costeiras da América do Sul Austral: Lagoa do Peixe ( $31^{\circ} \mathrm{S}, 51^{\circ} \mathrm{W} 0$, Brasil e Laguna Mar Chiquita (3705, 570W, Argentina. Neotropical Biology and Conservation, v 3, n 1, p. 28-33. 2008.

LÓPEZ, M.S; COUTINHO, R. Acoplamento Plâncton-Bentos: o papel do suprimento larval na estrutura das comunidades bentônicas de costões rochosos. Oecol, Brasili.,v. 12, p.575-601. 2008.

LUPPI, T.A; SPIVAK, E.D; BAS, C.C. The effects of temperature and salinity on larval development of Armases rubripes Rathbun, 1897 (Brachyura, Grapsoidea, Sesarmidae), and the southern limit of its geographical distribution. Estuar. Coast. Shelf Sci., n. 58, p.575-585. 2003.

MARQUES, W.C. Padrões de variabilidade temporal nas forçantes da circulação e seus efeitos na dinâmica da Lagoa dos Patos, Brasil. 87f. 2005. Dissertação (Mestrado Oceanografia Física, Química e Geológica) - Universidade do Rio Grande, Rio Grande do Sul, Brasil.

MELO, G.A.S. Manual de identificação dos Brachyura (caranguejos e siris) do litoral brasileiro. São Paulo: Plêiade Fapesp, 1996. 604 p.

MENDES, G.N; VALENÇA, A.R. Observações preliminares sobre o desenvolvimento larval do Caranguejo Aranha Stenorhynchus seticornis (HERBST, 1788) (DECAPODA: BRACHYURA: MAJIDAE) em laboratório. Bol. do Inst. de Pesca, São Paulo, v. 2, n. 34, p.325-329. 2008.

MÖLLER, O.O; CASTAING, P. Hydrographical Characteristics of the Estuarine Area of Patos Lagoon (30'S, Brazil). In: GME Perillo, MC Piccolo, MP Quivira, (Eds.), Estuaries of South America. Springer-Verlag, p. 83-100. 1999.

MÖLLER, O.O; CASTAING, P; SALOMON, J.C; LAZURE, P. The influence of local and nonlocal forcing effects on thesubtidal circulation of Patos Lagoon. Estuaries, v 24, n 2, p. 297-311. 2001.

MÖLLER, O.O; LORENZZETTI, J.A; STECH， J.L; MATA, M.M. The Patos Lagoon summertime circulation and dynamics. Cont. Shelf Res. v 16, p. 35 - 351. 1996 
ARAúJO, P. H. V. de; MUELBERT, J. H.; CALAZANS, D. K. de. Estudo do fluxo larval de braquiúros no canal de acesso ao estuário da Lagoa dos Patos, Rio Grande, Rio Grande do Sul, Brasil..

MÖLLER, O.O; PAIM, O.S; SOARES, I.D. Facteurs et mecanisms de La circulation dês eaux dans l'estuaire de la lagune dos Patos (RS, Bresil). Bull. Inst. Geol. Basin D'aquitaine. Bordeaux. França. v 49, 15-28. 1991.

MÖLLER, O.O; PIOLA, A.R; FREITAS, A.C; CAMPOS, E.J.D. The effects of river discharge and seasonal winds on the shelf off southeastern South America. Cont. Shelf Res.. v 28, n 13, 1607-1624. 2008.

MONTÚ, M.A. Zooplâncton do estuário da Lagoa dos Patos. 1. Estrutura e variações temporais e espaciais da comunidade. Atlântica, 4: 53-72. 1980.

MONTÚ, M.A; ANGE, K; BAKKER, C. Variability in the larval development of Metasesarma rubripes (Decapoda, Grapsidae) reared in the laboratory. Nerítica, Pontal do Sul, v. 1, n. 5, p.113-128. 1990.

MOTTA, V.F. Relatório-diagnóstico sobre a melhoria e o aprofundamento do acesso pela Barra de Rio Grande. Relatório Técnico Instituto Pesquisas Hidráulicas, Universidade Federal do Rio Grande Sul, Porto Alegre. 1969.

MUELBERT, J.H; WEISS, G. Abundance and distribution of fish larvae in the channel area of the Patos Lagoon estuary, Brazil. In: Hoyt, R. D. (Ed.). Larval fish recruitment in the Americas. Proceedings of the thirteenth annual fish conference. Merida, Mexico, NOAA Technical Report NMFS, 95, 1991, p. 43 - 54.

NEGREIROS-FRANSOZO, M.L; FRANSOZO, A; GONZÁLEZ-GORDILLO, J.I; BERTINI, G. First appraisal on releasing and reinvasion of decapod larvae in a subtropical estuary from Brazil. Acta Limnol. Bras., v 14, n 3, 87-94. 2002.

NG, P.K.L; GUINOT, D; DAVIE, P.J.F. Systema Brachyurorum: Part I. An annotated checklist of extant Brachyuran crabs of the world. The Raffles Bull. Of Zool., Singapore, n. 17, p.1-286. 2008.

PAPADOPOULOS, I; WOOLDRIDGE, T.H; NEWMAN, B.K. Larval life history strategies of sub-tropical southern African estuarine brachyuran crabs and implications for tidal inlet management Wetlands Ecology and Management 10: 249-256. 2002.

PAULA, J. Rhythms of larval release of decapod crustaceans in the Mira Estuary, Portugal. Marine Biology, v 100, p. 309-312. 1989.

PAULA, J; BARTILOTTI, C; DRAY, T; MACIA, A; QUEIROGA, H. Patterns of temporal occurrence of brachyuran crab larvae at Saco mangrove creek, Inhaca Island (South Mozambique): implications for flux and recruitment. J. Plankton Res., v. 26, n. 10, p.1163-1174. 2004.

PINHEIRO, M.A.A; FRANSOZO, A. Reproduction of the speckled swimming crab Arenaeus cribrarius (Brachyura: Portunidae) on the brazilian coast near $23^{\circ} 30^{\prime} \mathrm{S}$. J. Crust. Biol., Lawrence, v. 2, n. 22, p.416-428. 2002.

PINHEIRO, M.A.A; FRANSOZO, A; NEGREIROS-FRANSOZO, M.L. Estimativa da duração larval em função da temperatura para a Família Majidae (CRUSTACEA, DECAPODA, BRACHYURA). Bol do Inst. de Pesca, São Paulo, n. 21, p.75-81. 1994.

PIOLA, A.R; MATANO, R.P; PALMA, E.D; MÖLLER, O.O; CAMPOS, E.J.D. The influence of the Plata River discharge on the western South Atlantic shelf, Geophys. Geoph. Res. Lettl., v 32, L01603. 2005.

RHYNE, A; LIN, J; LEGEN, J. Laboratory culture of the green emerald crab: Mithraculus sculptus (Decapoda: Brachyura: Majidae). In: WORLD AQUACULTURE 2003 - Book of Abstracts, Salvador, 2003, p. 629.

RIEGER, P.J; SANTOS, A.L.F. Desenvolvimento larval de Chasmagnathus granulata Dana (Crustacea, Decapoda, Grapsidae), em laboratório. I. Estudo da morfologia de cerdas nas fases de zoea e megalopa e das variações dos padrões corporais da fase de megalopa. Rev. Bras. de Zool., Curitiba, v. 4, n. 18, p.1281-1317. 2001. 
ARAúJO, P. H. V. de; MUELBERT, J. H.; CALAZANS, D. K. de. Estudo do fluxo larval de braquiúros no canal de acesso ao estuário da Lagoa dos Patos, Rio Grande, Rio Grande do Sul, Brasil.

ROMAN, M.R; BOICOURT, W.C. Dispersion and recruitment of crab larvae in the Chesapeake Bay plume: physical and biological controls. Estuaries 22 (3): 563-574. 1999.

ROUGHGARDEN, J; GAINES, S; POSSINGHAM, H. Further support for the hypothesis that internal waves can cause shoreward transport of larval invertebrates and fish. Science, $v$. 4872, n. 241, p.1460-1466. 1988.

ROWE, P.M; EPIFANIO, C.E. Tidal stream transport of weak fish in Delaware Bay, USA. Mar. Ecol. Prog. Ser., v. 110, p.105-114. 1994.

SAIGUSA, M; OKOCHI, T; IKEI, S. Nocturnal occurrence and synchrony with tidal and Iunar cycles in the invertebrate assemblage of a subtropical estuary. Acta Oecologica 24: 191-204. 2003.

SANDIFER, P.A. Distribution and abundance of decapod larvae in the York River estuary and adjacent lower Chesapeake Bay, Virginia, 1968-1969. Ches. Sci., n. 14, p.235-257. 1973.

SANDIFER, P.A. The role of pelagic larvae in recruitment to populations of adult decapod crustaceans in the York River estuary and adjacent lower Chesapeake Bay, Virginia. Estuar. And Coast. Mar. Sci., n. 3, p.269-279. 1975.

SCHMITT, V.B. Transporte diferencial de ovos e larvas de peixes na desembocadura do estuário da Lagoa dos Patos. Rio Grande, 56f. 2010. Monografia (Graduação em Oceanologia) - Instituto de Oceanografia. Universidade Federal do Rio Grande.

SCHWAMBORN, R; MELO JÚNIOR, M; LEITÃO, S.N; EKAU, W; PARANAGUÁ, M.N. Dynamic patterns of zooplankton transport and migration in Catuama Inlet (Pernambuco, Brazil), with emphasis on the decapod crustacean larvae. Lat. Am. J. Aquat. Res., $\mathrm{n}^{\circ}$ 36, v 1, p.109-113. 2008.

SHANKS, A.L. Mechanisms of cross-shelf dispersal of larval invertebrates and fish. In: L.R. MacEdward (ed.). Ecol. of Mar. Invertebr. Larv., CRC Press, London, p. 323 - 367. 1995.

SILVA P.V; LUPPI, T.A; SPIVAK, E.D; ANGER, K. Reproductive traits of an estuarine crab, Neohelice (= Chasmagnathus) granulata (Brachyura: Grapsoidea: Varunidae), in two contrasting habitats. Sci Mar, v 73, no 1, p.117-127. 2009.

SILVA-FALCÃO, B.E.C; SEVERI, W; ROCHA, A.A.F. Dinâmica espacial e temporal de zoeas de Brachyura (Crustacea, Decapoda) no estuário do Rio Jaguaribe, Itamaracá, Pernambuco. Iheringia Série Zool., Porto Alegre, v. 4, n. 97, p.434-440. 2007.

STUCK, K.C; TRUESDALE, F.M. Larval development of the speckled swimming crab, Arenaeus cribrarius (Decapoda: Brachyura: Portunidae) reared in the laboratory. Bull. Mar. Sci., v. 1, n. 41, p.101-132. 1988.

TAVARES, M, MENDONÇA JR, JB. Introdução de Crustáceos Decápodes Exóticos no Brasil. In: Água de Lastro e Bioinvasão, 1, Rio de Janeiro, Interciência, p. 65 - 66. 2004.

TEIXEIRA, R.L; SÁ, HD. The use of bromeliads as an alternative shelter by the grapsid crab, Metasesarma rubripes (Rathbun, 1897) of southeast Brazil. Bol. do Mus. de Biol. Mello-leitão, Vitória, n. 8, p.13-20. 1998.

TOMAZELLI, L.J. O regime de ventos e taxa de migração de dunas eólicas costeiras do Rio Grande do Sul, Brasil. Pesquisas, v. 1, n. 20, p.18-26. 1993.

VAZ, A.C; MÖLLER, O.O; ALMEIDA, T.L. Análise quantitativa da descarga dos rios afluentes da Lagoa dos Patos. Atlântica, Rio Grande. v 28, n 1, 13-23. 2006.

VIEIRA, E.F; RANGEL, S.R.S. Planície Costeira do Rio Grande do Sul: geografia física, vegetação e dinâmica socio-demográfica. Sagra Editora, Brasil. 1988, 256p. 
VIEIRA, J.P; CASTELLO J.P. Fish fauna. In: U. SEELIGER, C. ODEBRECHT \& J.P. CASTELLO (EDs). Subtropical convergence marine ecosystem. The coast and the sea in the warm temperate southwestern atlantic. New York, Springer Verlag, p. 56-61. 1996.

VIEIRA, R.R.R. Identificação, abundância e distribuição das fases larvais das espécies de Brachyura (Crustacea, Decapoda) no estuário da Lagoa dos Patos e região costeira. Rio Grande, 203f. 2006. Tese (Doutorado Oceanografia Biológica) - Instituto de Oceanografia. Universidade Federal do Rio Grande.

VIEIRA, R.R.R; CALAZANS, D.K. Chave ilustrada para as zoés de Brachyura do estuário da Lagoa dos Patos (RS) e região costeira adjacente. Biot. Neotr., v 10, n 3, 431-437. 2010.

VIEIRA, R.R.R; RIEGER, P.J. Larval development of Hexapanopeus caribbaeus (Stimpson, 1871) (Crustacea, Decapoda, Xanthoidea, Panopeidae) reared under laboratory conditions. J. of Crust. Biol., Inglaterra, v. 10, n. 26, p.1175-1182. 2004.

ZAVIALOV, P; MÖLLER, O.O; CAMPOS, E.J.D. First direct measurements of currents on the continental shelf of Southern Brazil. Cont. Shelf. Res., v 22, n 14, 1975-1986. 2002. 